\title{
An examination of the sensitivity of the Great Salt Lake to changes in inputs
}

\author{
Ibrahim Nourein Mohammed ${ }^{1}$ and David G. Tarboton ${ }^{2}$ \\ Received 9 February 2012; revised 1 October 2012; accepted 1 October 2012; published 9 November 2012.
}

[1] The Great Salt Lake is a closed basin lake in which level and volume fluctuate due to differences between inflows and outflows. The only outflow is evaporation, which depends directly on lake area and salinity, both of which depend on lake volume. The lake's level, volume, and area adjust to balance, on average, precipitation and streamflow inflows by evaporation. In this paper, we examine the sensitivity of lake volume changes to precipitation, streamflow, and evaporation and the interactions among these processes and lake area and salinity related to volume. A mass balance model is developed to generate representative realizations of future lake level from climate and streamflow inputs simulated using the $k$-nearest-neighbor method. Climate and salinity are used to estimate evaporation from the lake using a Penman model adjusted for the salinity-dependent saturation vapor pressure. Our results show that fluctuation in streamflow is the dominant factor in lake level fluctuations, but fluctuations in lake area that modulate evaporation and precipitation directly on the lake are also important. The results also quantify the sensitivity of lake level to changes in streamflow and air temperature inputs. They predict that a $25 \%$ decrease in streamflow would reduce lake level by about $66 \mathrm{~cm}(2.2$ feet $)$, while a $+4^{\circ} \mathrm{C}$ air temperature increase would reduce lake level by about $34 \mathrm{~cm}$ (1.1 feet) on average. This sensitivity is important in evaluating the impacts of climate change or streamflow change due to increased consumptive water use on the level of the lake.

Citation: Mohammed, I. N., and D. G. Tarboton (2012), An examination of the sensitivity of the Great Salt Lake to changes in inputs, Water Resour. Res., 48, W11511, doi:10.1029/2012WR011908.

\section{Introduction}

[2] Scientific Management of the Great Salt Lake (GSL) system requires a comprehensive understanding of the behaviors and physical processes that lead to level changes. The underlying physical processes that collectively produce changes in the GSL lake level operate at different spatial and temporal scales. Moreover, the relations between these physical processes are often nonlinear and the resulting complexities limit our ability to forecast the GSL level. There is thus a need to better understand the interactions between lake level, volume, area, evaporation and salinity in response to driving inputs of precipitation, streamflow and climate.

[3] This study uses an elasticity measure, defined as the ratio of the variability of streamflow, precipitation, evaporation, area and salinity to the variability in historic volume changes, in order to examine the sensitivity of GSL volume to inputs and factors internal to the dynamics of the system.

\footnotetext{
${ }^{1}$ EPSCOR, University of Vermont, Burlington, Vermont, USA.

${ }^{2}$ Utah Water Research Laboratory, Logan, Utah, USA.
}

Corresponding author: I. N. Mohammed, EPSCOR, University of Vermont, 82 University P1., 529 Cook Physical Science Bldg., Burlington, VT 05405-1706, USA. (ibrahim.mohammed@uvm.edu)

(C)2012. American Geophysical Union. All Rights Reserved. 0043-1397/12/2012WR011908
A mass balance model, developed as part of this study, was used to physically simulate lake level and volume. Model inputs are precipitation, streamflow, air temperature, wind speed and humidity. The model tracks lake volume, level, area and salinity and uses Penman's equation adjusted for the salinity dependent saturation vapor pressure to calculate evaporation. While the lake model is physically based, we use statistical methods to simulate the exogenous climate and streamflow inputs, effectively assuming that past inputs are statistically representative of the range of potential future inputs. The model uses $k$-nearest-neighbor resampling [Lall and Sharma, 1996] to reproduce the stochastic dependence of total annual inputs to the lake, drawing from input data compiled over 61 years (1950-2010).

[4] This model was used to forecast the distribution of future lake levels over a time scale of 30 years. The model was then used to quantify the sensitivity of the distribution of future lake levels to changes in streamflow or air temperature inputs. Streamflow input to the lake may change due to water resources development and consumptive use in the drainage basin, while air temperature may change due to changing climate. This model helps to quantify the impact of such changes on the lake. We found that the time scale for the lake to adjust to input fluctuations is on the order of 5 years. Historic streamflow fluctuations at this 5 year time scale are about $\pm 25 \%$ of the annual streamflow input to the lake. The model predicts that a $25 \%$ increase in streamflow would increase the GSL level by about $55 \mathrm{~cm}$ ( $1.8 \mathrm{feet})$ on 
average; while a $25 \%$ decrease in streamflow input to the lake would reduce the level by about $66 \mathrm{~cm}$ ( $2.2 \mathrm{feet})$ on average. The North American Regional Climate Change Assessment Program (NARCCAP) indicates potential warming in the range of $3^{\circ} \mathrm{C}$ to $4^{\circ} \mathrm{C}$ for this region [Mearns et al., 2007, 2009]. We adjusted monthly minimum, maximum and dew point temperature by $+4^{\circ} \mathrm{C}$ in model inputs to evaluate the sensitivity to, and potential impact of, this warming and found that the GSL level would decrease by about $34 \mathrm{~cm}$ (1.1 feet) on average. These sensitivities are important in evaluating the impacts of water resources and climate induced streamflow and temperature input changes on the GSL.

[5] In this paper, we first give a background of the GSL, review literature on forecasting the GSL volumes and levels, introduce the concepts of elasticity and nearest neighbor resampling used in this study, followed by a description of the methods used to assemble and analyze input data. We then describe the GSL mass balance model (GSLMBM) that we have developed and present results from the analysis of historic data and model simulations.

\section{Background}

\subsection{Great Salt Lake Information}

[6] The GSL (latitude $40.7^{\circ}$ to $41.7^{\circ} \mathrm{N}$, longitude $111.9^{\circ}$ to $113.1^{\circ} \mathrm{W}$ ) is located in the northeast of the Great Basin and is the fourth largest perennial and closed basin lake in the world (Figure 1). The GSL is a remnant of freshwater Lake Bonneville, which existed from about 10 to 30 thousand years ago [Fenneman, 1931]. The GSL level and volume fluctuate due to differences between inflows and outflows. Evaporation, the only outflow, is dependent on lake area and salinity, both of which are affected by lake volume. On average, the lake volume adjusts to balance precipitation and streamflow inflows by evaporation. The lake is shallow (average depth 4-6 m), with a large and variable surface area $\left(3000-6000 \mathrm{~km}^{2}\right)$, and its salinity ranges from $5 \%$ to $28 \%$. The GSL basin covers portions of northern Utah, southern Idaho and western Wyoming and has an area of about $55,000 \mathrm{~km}^{2}$.

[7] For this study, lake level data were retrieved from the USGS Water Data Discovery Web page (http://water.usgs. gov/data.html, accessed on 13 June 2005) and then updated from the USG Water Data for the Nation Web page (http:// waterdata.usgs.gov/nwis, accessed on 1 April 2011) for the south arm (USGS 10010000, Great Salt Lake at Saltair Boat Harbor) and the north arm (USGS 10010100, Great Salt Lake near Saline). These data incorporate USGS benchmark corrections given at http://ut.water.usgs.gov/greatsaltlake/ elevations/gslcorrection.html [Loving et al., 2000]. The earliest level data point available is from 18 October 1847. USGS lake level measurements were first made in 1875 ; lake level values prior to this date were estimates based on observer reports.

[8] The GSL level has fluctuated between the lowest recorded level of $1278.5 \mathrm{~m}$ (4194.4 feet) in 1963 (15 October 1963 ) and highest level of 1283.7 (4211.6 feet) recorded in 1872, 1873 and in 1986 (3 June 1986) over the historic record available since 1847 (Figure 2). The annual 25th, 50th, and 75th percentiles for the Great Salt Lake level during the 1847-2010 period are $1279.3 \mathrm{~m}$ (4197.1 feet), $1280.4 \mathrm{~m}$
(4200.9 feet) and $1281.2 \mathrm{~m}$ (4203.4 feet), respectively. Figure 2 shows that GSL level fluctuations occur over time scales of 5 to 20 years and longer. Superimposed on these longer cycles is an annual scale with fluctuation of about $0.5 \mathrm{~m}$ ( 1 to 2 feet), rising during winter and spring runoff (November to June) then dropping during summer (July to October) when evaporation is high and inflows are low. The volume of the Great Salt Lake fluctuates with its level, resulting in concentration or dilution of the salt in the lake, affecting surface salinity. Water residence time in the lake is about 5 years, which is also the time scale implied by the historical range of volume changes (active volume) in comparison to mean inflows [Mohammed and Tarboton, 2011].

[9] GSL level fluctuations are of direct concern to industries and infrastructure along the shore such as the Salt Lake City Airport, the Union Pacific Railroad, wastewater treatment plants and Interstate highway 80 [Lall et al., 1996]. GSL level fluctuations are also well correlated with regional water supply conditions. During 1983-1986 the Great Salt Lake rose rapidly to its highest level in a hundred years and then declined quickly. A pumping project (the West Desert Project) was initiated due to that event at a cost of about $\$ 60$ million. The project removed more than $3.08 \mathrm{~km}^{3}$ (2.5 million acre-feet) of water and 695 million tons of salt from the lake from April 1987 to June 1989. From January 1990 to June 1992, $0.25 \mathrm{~km}^{3}$ (200,000 acrefeet) of this pumped water and 94 million tons of salt returned to the lake [Wold and Waddell, 1994; Loving et al., 2000]. The following two decades (1990-2010) have seen low lake levels raising concerns that the GSL might be drying up. A lower GSL level leads to higher salinity in the lake, while less water reduces shoreline perimeter and results in islands becoming connected to the mainland. Such outcomes have ramifications for lake ecology and human health. Ecologically, a reduced shoreline means reduced bird habitat. Human health effects include the contribution of exposed lake bed sediments to respirable dust concentrations [Bedford, 2009].

\subsection{Great Salt Lake Level Prediction}

[10] Prior research has taken a statistical and systems dynamics approach to predicting the volume and level of the GSL [Lall et al., 2006; Moon et al., 2008; Wang et al., 2010]. This approach exploits the idea that the GSL is a lowfrequency filter of climate inputs. Prediction approaches strive to capture nonlinear dependency, predicting future volumes from past volumes in a dynamical systems state or phase space [Abarbanel and Lall, 1996; Abarbanel et al., 1996].

[11] Lall et al. [2006] presented an application of a multivariate, nonparametric regression approach to forecast the biweekly GSL volume time series (a short-term forecast of 1 year) arguing that their local polynomial regression scheme could be an alternative to multivariate adaptive regression splines (MARS) [Friedman, 1991]. Lall et al.'s [2006] approach uses a fraction of the full sample (part of the time series) to estimate the parameters of the local regression model and provides an improvement in algorithms that develop predictions from multivariate data structures.

[12] Moon et al. [2008] and Moon and Lall [1996] studied the relationships between the time variability of the volume of GSL and selected atmospheric circulation indices. 


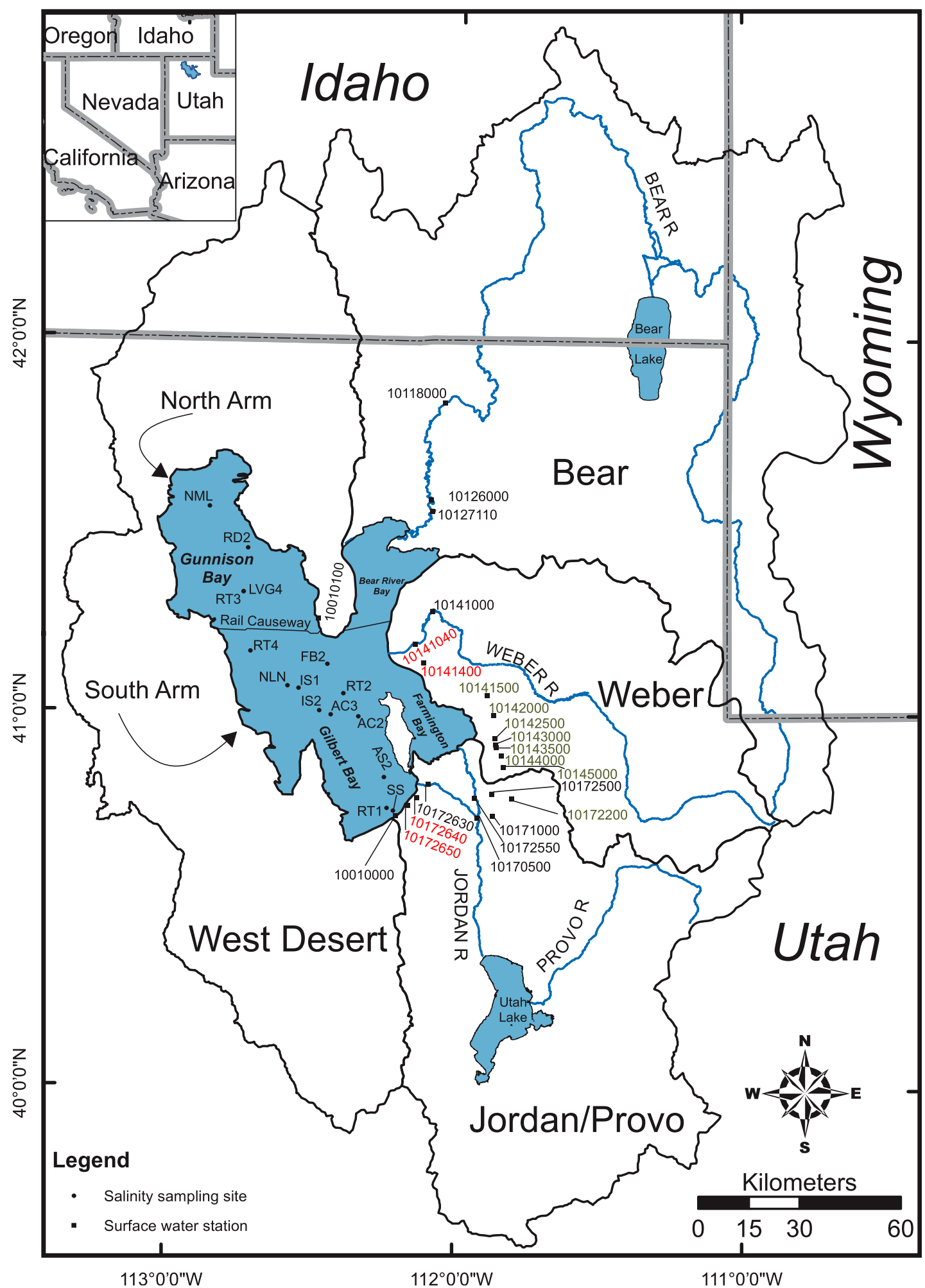

Figure 1. Location of the Great Salt Lake, subbasins that drain to it, and data collection sites used to estimate inflow, water surface altitude, and salt load. Gray labeled surface water stations represent Davis County inflow to the Great Salt Lake, red labeled stations represent other surface inflow, and black labeled stations represent the primary drainages as well as Great Salt Lake level stations. 


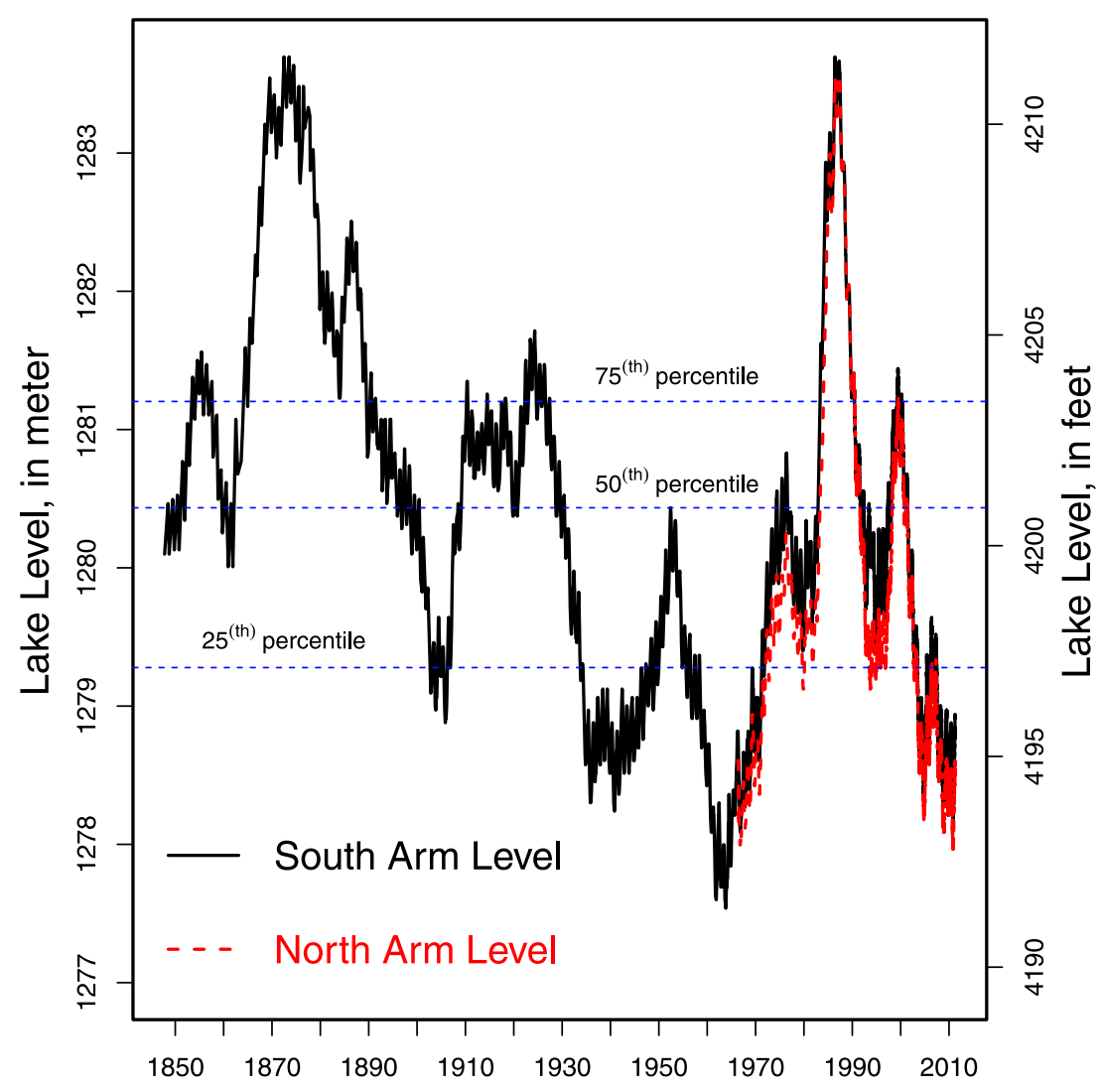

Figure 2. Historic Great Salt Lake levels. The lake was divided into north and south arms by a railroad causeway in 1959.

They developed and applied nonlinear measures of dependence between atmospheric circulation indices and the GSL volume at various lags (presuming that these indices are considered to lead the GSL volume) to develop forecasts of the volume of the GSL using selected atmospheric circulation indices. The indices considered were the Southern Oscillation Index (SOI), the Pacific-North America (PNA) climatic pattern and the Central North Pacific (CNP) climatic pattern. Moon et al. [2008] applied the local weighted polynomials methodology discussed by Lall et al. [2006] to predict the volume of the GSL using both the above mentioned atmospheric indices and previous lake volumes and suggested that predictions of GSL volumes using the local polynomial regression approach can lead to significant improvements in the predictability of lake volume.

[13] Wang et al. [2010] presented a methodology to predict the precipitation variation in the Great Basin and the GSL level for subsequent years using the Pacific QuasiDecadal Oscillation (QDO) index. They also discussed the physical link between the Pacific QDO index and the hydrological processes in the Great Basin region. Wang et al. [2010] found that the GSL level lags precipitation in the Great Basin by about 3 years and the GSL level takes an average of 6 years to respond to the Pacific QDO index. These associations with longer-term patterns present an important opportunity for longer-term GSL level forecasts.

[14] In summary, this prior research has examined several methods for forecasting GSL levels or volumes based on statistical or dynamical systems approaches, or measures of dependence between selected atmospheric circulation indices and the GSL volume. While this dynamical systems approach has provided improved predictive capability, the empirical nonlinear relationships that underlie the methods do not decompose the GSL system into its component processes. Therefore, the approach is neither intended for nor suited to evaluating the sensitivity of lake level to regional management practices (watershed changes such as consumptive use, withdrawals, urbanization, deforestation, etc.) in the GSL basin, nor is it able to address how lake level is impacted by climate change that leads to changes in evaporation from the lake. The approach also provides no capability for directly assessing impacts of lake management such as mineral pond withdrawals and bathymetry alterations.

[15] The physically based modeling approach used in this study is intended to address these questions.

\subsection{Elasticity}

[16] Schaake [1990] adapted the concept of elasticity used in economics to define the elasticity of runoff to change in precipitation:

$$
\varepsilon_{p}(P, Q)=\frac{d Q / Q}{d P / P}=\frac{d Q}{d P} \frac{P}{Q}
$$

where $P$ is precipitation falling on a watershed and $Q$ is runoff leaving a watershed. This quantifies the sensitivity of runoff to changes in precipitation and is also referred to as a sensitivity factor by Dooge [1992] and Dooge et al. [1999] 
and magnification factor by Kuhnel et al. [1991]. A number of other studies have used and extended this concept [Yates and Strzepek, 1998; Sankarasubramanian et al., 2001; Arnell, 2002; Chiew, 2006; Fu et al., 2007a, 2007b, 2007c].

\subsection{Autocorrelation Function}

[17] The autocorrelation function (ACF) measures the amount of linear dependence between observations in a time series that are separated by lag $k$ [Hipel et al., 1977]. The ACF helps in identifying the nature of short- and longterm persistence in time series analysis. The complexity of water resources management problems often requires stochastic models that can reproduce statistical properties of the historic data such as statistical dependence quantified by the ACF. One such model is the $k$-nearest-neighbor $(k$-nn) model [Lall and Sharma, 1996]. The $k$-nn model is a nonparametric method that makes few assumptions about the underlying distribution of the data and is useful for the Monte Carlo simulation of hydrologic time series for water resources analysis, design and operation problems.

\section{Analysis of Historic Data}

[18] The bathymetry of the GSL has been compiled by the USGS in tables that report the volume and area of the lake for a range of levels. The GSL bathymetry data sources that we are aware of are (1) the north and south arms, volume-area tables for levels 1271.3 to $1285 \mathrm{~m} \mathrm{(4171.0} \mathrm{to}$ 4216 feet) [Loving et al., 2000], (2) the south arm, volumearea tables for levels 1270 to $1280 \mathrm{~m}$ (4167.0 to 4200 feet) but excluding Farmington and Bear River Bays [Baskin, 2005], and (3) the north arm, volume-area tables for levels 1270 to $1280 \mathrm{~m}$ (4167.0 to 4200 feet) [Baskin, 2006]. In this work we used the Loving et al. [2000] bathymetry tables because they provide estimates of volume and area for levels greater than $1280 \mathrm{~m}$ and cover the entire lake. Lake levels, together with the bathymetry, were used to determine lake area and volume.

[19] Streamflow gauging information and estimates for surface water inflow to the GSL are tabulated in the Appendix (Tables A1 and A2). Figure 3 gives the annual average streamflow input to the Great Salt Lake from the Bear, Weber and Jordan rivers as well as other tributaries draining to the lake. The annual average streamflow input to the GSL is about $3 \mathrm{~km}^{3}$, with about $58 \%$ of that coming from the Bear River (Table 1).

[20] Groundwater inflow to the GSL was estimated to be $0.093 \mathrm{~km}^{3}$ (75,000 acre-feet $\left.\mathrm{yr}^{-1}\right)$ [Waddell and Barton, 1980; Loving et al., 2000].

[21] Direct precipitation on the lake and minimum, maximum and dew point temperatures over the lake were obtained from the Oregon State University PRISM Climate Group (http://www.prism.oregonstate.edu/) [Daly et al., 2008] for the period October 1949 to September 2010. This data is reported monthly on a $2.5 \operatorname{arc} \min (\sim 4 \mathrm{~km})$ grid. Grid cells falling within each arm of the GSL were identified and data from these grid cells were averaged to produce time series of monthly precipitation and air temperatures. Annual averages are depicted in Figures 4 and 5. Precipitation, streamflow, groundwater and west desert pumping withdrawals and return flow were summarized for the GSL system during the 1950-2010 time period (Figure 6).

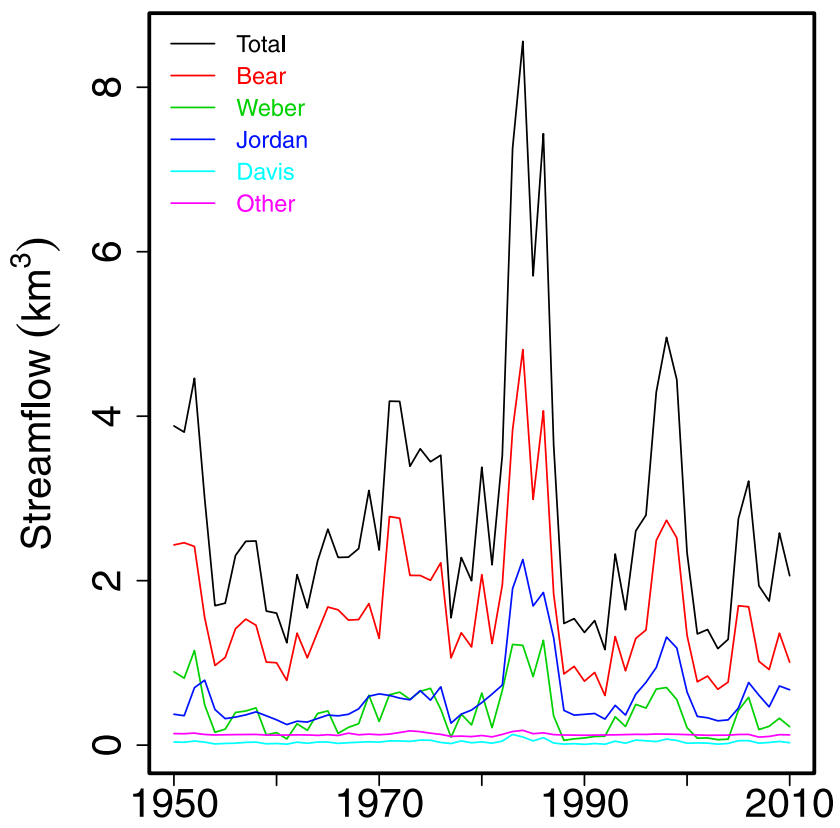

Figure 3. Annual average streamflow input to the Great Salt Lake.

[22] Gridded meteorological data from the University of Washington for the Great Basin, as described by Hamlet and Lettenmaier [2005], was retrieved from http://www.hydro. washington.edu/Lettenmaier/Data/gridded/index_hamlet.html. This is daily data in a $7.5 \mathrm{~min}$ grid $(\sim 15 \mathrm{~km})$. Grid cells falling within each arm of the GSL were identified, and data from these grid cells were averaged to produce time series of monthly wind speed for the period October 1949 to September 2010. Monthly wind speed for the period January 2004 to September 2010 is not available from the University of Washington but was estimated using longterm averages from the available years of the University of Washington wind speed data.

[23] Salinity observations made by the Utah Geological Survey (UGS) have included brine density, temperature, ion concentrations and total dissolved solids (TDS) recorded at multiple depths within both arms of the GSL. We obtained data for the period 1966-2007 from E. Gaddis (unpublished data, 2011) that extends the time period compared to the data used in previous published studies [Loving et al., 2000]. These data were used to estimate the salinity in both arms of the lake, as well as the salt load defined as the mass of dissolved solids in either arm or the lake as a whole. The locations of the 17 salinity sites where data were obtained are shown in Figure 1. These salinity sites included 5 sites in the north arm (LVG4, NML, RD2, RT3 and ECN) and 12 sites in the south arm of the GSL (FB2, AS2, RT2, RT4, NLN, $\mathrm{AC} 3, \mathrm{SS}, \mathrm{AC} 1, \mathrm{AC} 2, \mathrm{IS} 1, \mathrm{IS} 2$ and RT1). Brine density measurements were recorded at multiple depths within both arms of the lake in order to quantify the density and salinity

Table 1. Annual Average Great Salt Lake Streamflow Input

\begin{tabular}{|c|c|c|c|c|c|c|}
\hline & Bear & Weber & Jordan & Davis & Other & Total \\
\hline Input $\left(\mathrm{km}^{3}\right)$ & 1.65 & 0.41 & 0.61 & 0.04 & 0.13 & 2.84 \\
\hline Percentage of input & 58 & 15 & 22 & 1 & 5 & 100 \\
\hline
\end{tabular}




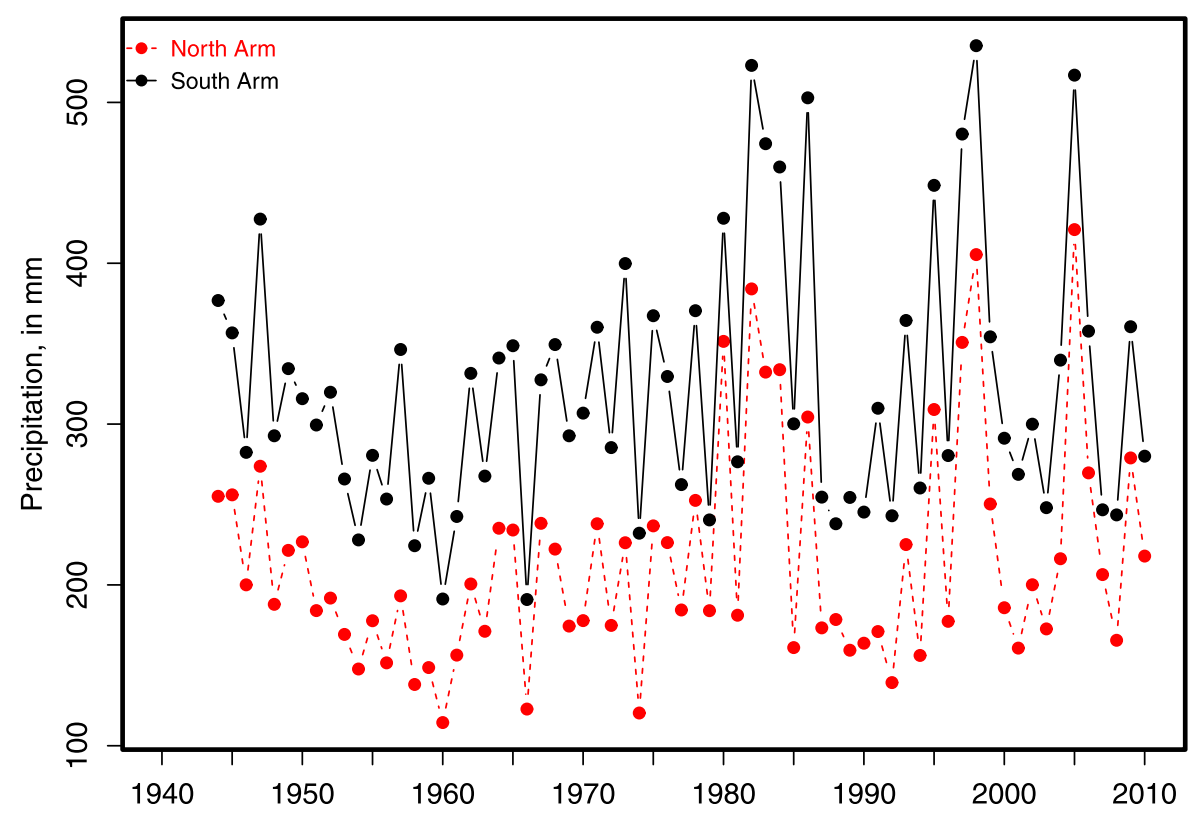

Figure 4. Annual total precipitation onto the Great Salt Lake from PRISM.

stratification that occurs in the GSL [Loving et al., 2000]. The density/salinity measuring program has been such that data are collected sporadically at the sites indicated in Figure 1, seldom on the same day at multiple sites. The data set contains data collected at each site from 0 to 12 times per year over the period of record. The GSL brine concentrations are related to densities of brine [Loving et al., 2000] through

$$
\rho_{b 20}=\rho_{w 20}+0.63 C
$$

where $\rho_{w 20}$ is the density of freshwater $\left(1 \mathrm{~g} \mathrm{~cm}^{-3}\right)$ at $20^{\circ} \mathrm{C}$, $\rho_{b 20}$ is the density of brine $\left(\mathrm{g} \mathrm{cm}^{-3}\right)$ at $20^{\circ} \mathrm{C}$, and $C$ is the brine concentration $\left(\mathrm{g} \mathrm{cm}^{-3}\right)$. Waddell and Bolke [1973] relate the GSL brine density to freshwater density through temperature adjustment:

$$
\rho_{b}=\rho_{b 20} \cdot \rho_{w} / \rho_{w 20}
$$

where $\rho_{w}$ is the density of freshwater equal to $\left(8 T-T^{2}+\right.$ 132416)/132432 $\left(\mathrm{g} \mathrm{cm}^{-3}\right)$ for temperature $T\left({ }^{\circ} \mathrm{C}\right)$ and $\rho_{b}$ is the density of brine at any temperature.

[24] On every day that density/salinity measurements were made at any site, we used that set of salinity records to estimate the salt load, $L$, of the arm of the lake in which the site resides. To calculate salt load based on the range of density measurements over depth on any date, the lake arm was divided into layers (Figure 7) and each layer load was evaluated. Bathymetry and lake level were used to estimate the volume for each layer. For the lake at level $h$, the interfaces between layers are $h-\left(z_{1}+z_{2}\right) / 2, h-\left(z_{2}+z_{3}\right) / 2$, and so on for remaining layers. The volume of layer 1 was then calculated from the bathymetry volume-level relationship as $V(h)-V\left(h-\left(z_{1}+z_{2}\right) / 2\right)$. The volume of layer 2 was calculated as $V\left(h-\left(z_{1}+z_{2}\right) / 2\right)-V\left(h-\left(z_{2}+z_{3}\right) / 2\right)$ and so on for remaining layers (Figure 7$)$. The total arm

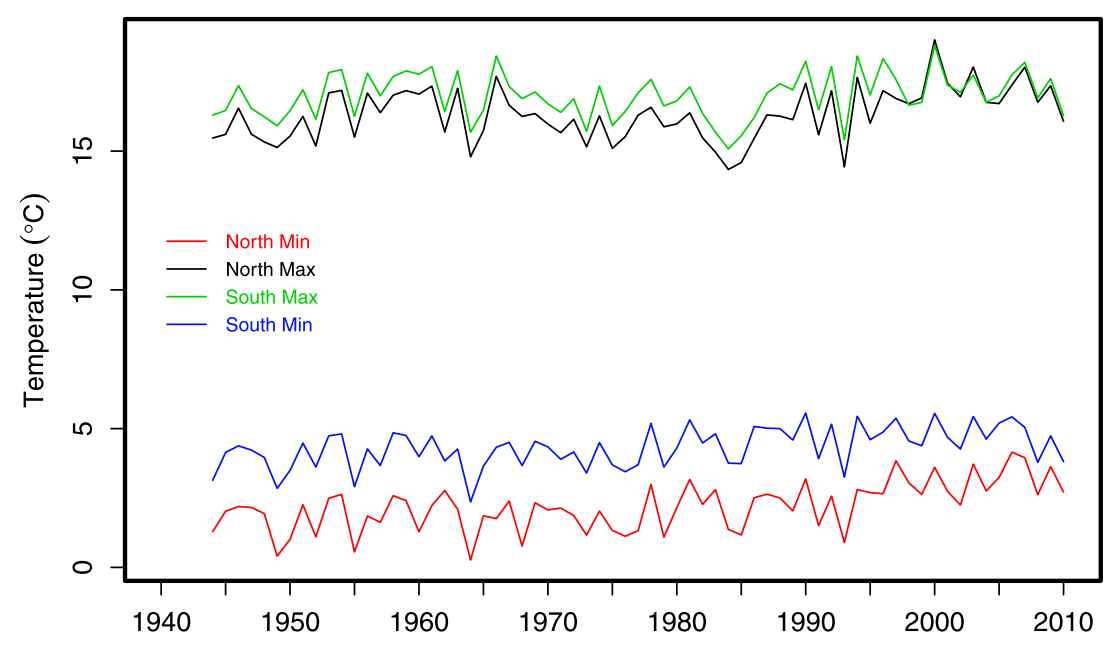

Figure 5. Annual averages of monthly minimum and maximum air temperature over the Great Salt Lake. 


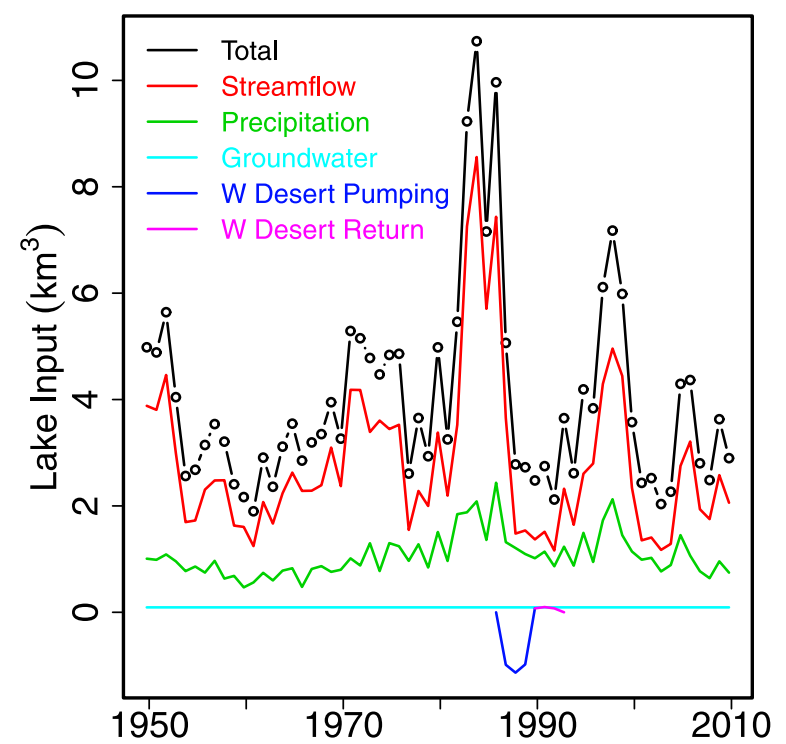

Figure 6. Great Salt Lake inputs summary.

salt load is then the sum of salt loads from each layer expressed by

$$
L=C_{1} V_{1}+C_{2} V_{2}+C_{3} V_{3}+\cdots
$$

In order to integrate over salinity stratification in the lake, we only calculated load on days when density/salinity at four or more depths was available. Observed average concentration was then estimated using

$$
C=\frac{L}{V}
$$

where $L$ is the GSL salt load (in $\mathrm{kg}$ or tons) and $V$ is the volume of the arm of the lake.

[25] To obtain a continuous salt load estimate in each arm of the lake, we smoothed the sporadic load estimates from all sites in that arm using loess $[R$ Development Core Team, 2010] with span parameter of 0.1 . The smoothed salt loads from each arm were then summed to estimate total GSL salt load (Figure 8). Note in Figure 8 that total load is roughly constant and that there is an anticorrelation between the load in each arm. This reflects the physical movement of salt between the two arms such that when load is increasing in one arm it is decreasing in the other. Figure 8 also gives the dates of west desert pumping and west desert return flows and shows that the total salt load peaks at times when the lake is high and salinities are well below saturation (1986). Following Loving et al. [2000], it can be assumed

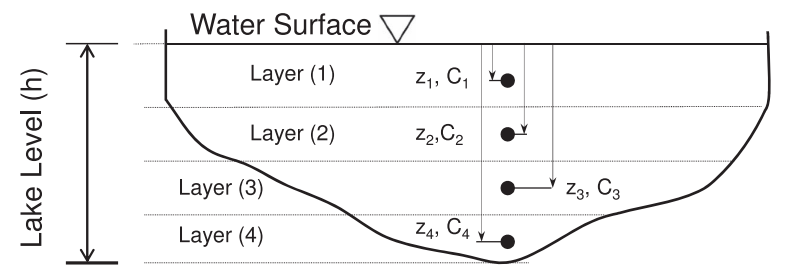

Figure 7. Diagram of a hypothetical lake arm divided into four layers used to calculate salt load. that at these high lake levels essentially all of the salt is dissolved. This suggests a total salt load in the GSL of 4.87 billion U.S. tons prior to the west desert pumping. Loving et al. estimated the total salt load to be 5.0 billion U.S. tons and Wold et al. [1997] estimated the total salt load to be 4.9 billion U.S. tons. These earlier studies used much of the same data we have used, so we assume the differences are due to slightly different methods (subdivision into layers) and are within the uncertainty of the data. When the total load is less than 4.87 billion U.S. tons, the difference is presumed to be precipitated salt in the north arm where concentrations are frequently at the saturation level, which for the GSL is $355 \mathrm{~g} / \mathrm{L}$ [Loving et al., 2000]. The salt load estimates in 1992 suggest a total load of 4.56 billion U.S. tons, representing a net loss of about 0.31 billion U.S. tons due to the west desert pumping (Figure 8). This net loss is somewhat less than the 0.6 or 0.5 billion U.S. tons reported by Loving et al. [2000], a difference that we attribute to methodological differences and measurement uncertainty. In Figure 8 precipitated and extracted salt load was estimated as the difference between these high lake level totals ( 4.87 billion U.S. tons prior to 1987 and 4.56 billion U.S. tons post 1992) and the current total salt load. Prior to 1987 this is interpreted as precipitated load since it redissolved to produce the 1987 load measurements. Following 1992 it is not possible to separate the effects of salt precipitation when the north arm is saturated and mineral extraction that reduces total salt load in the lake. Based on Figure 8, we infer the average salt load in the south arm as $1.81 \times 10^{12} \mathrm{~kg}$ (1.99 billion U.S. tons) and average salt load in the north arm as $2.29 \times 10^{12} \mathrm{~kg}$ (2.52 billion U.S. tons). Figure 8 shows that, overall, a greater fraction of the salt load is held in the north arm and that this fraction increases when the lake is high.

[26] In order to obtain continuous estimates of salinity for use in the calculation of lake evaporation outside the period when salinity was measured, we calculated the salinity in each arm of the lake using equation (5), bounded by the saturation level. This calculation assumed, as a first approximation, that the load in each arm was constant [Loving et al., 2000]. Specifically, we used

$$
C=\min \left(\left(L_{S}+L_{N}\right) /_{\left(V_{S}+V_{N}\right)}, 355\right)
$$

prior to closure of the causeway. After the closure of the causeway we used

$$
C_{S}=\min \left(L_{S} /_{V_{S}}, 355\right) ; \quad C_{N}=\min \left(L_{N} / V_{N}, 355\right)
$$

where $C$ refers to concentration $\left(g L^{-1}\right) L$ is salt load, $V$ is volume and subscripts $N$ and $S$ refer to the north arm and south arm of the lake. In these equations, average north arm and south arm salt loads estimated above, i.e., $L_{N}=$ $2.29 \times 10^{12} \mathrm{~kg}$ and $L_{S}=1.81 \times 10^{12} \mathrm{~kg}$, were used. The causeway closure was taken to be on 1 January 1960. We treated the lake as a single water body prior to causeway closure. Figure 9 compares salinity estimates from these equations with observed concentrations. Note that in Figure 9 there are no salinity observations prior to and immediately after the causeway closure (observations started in 1966). 


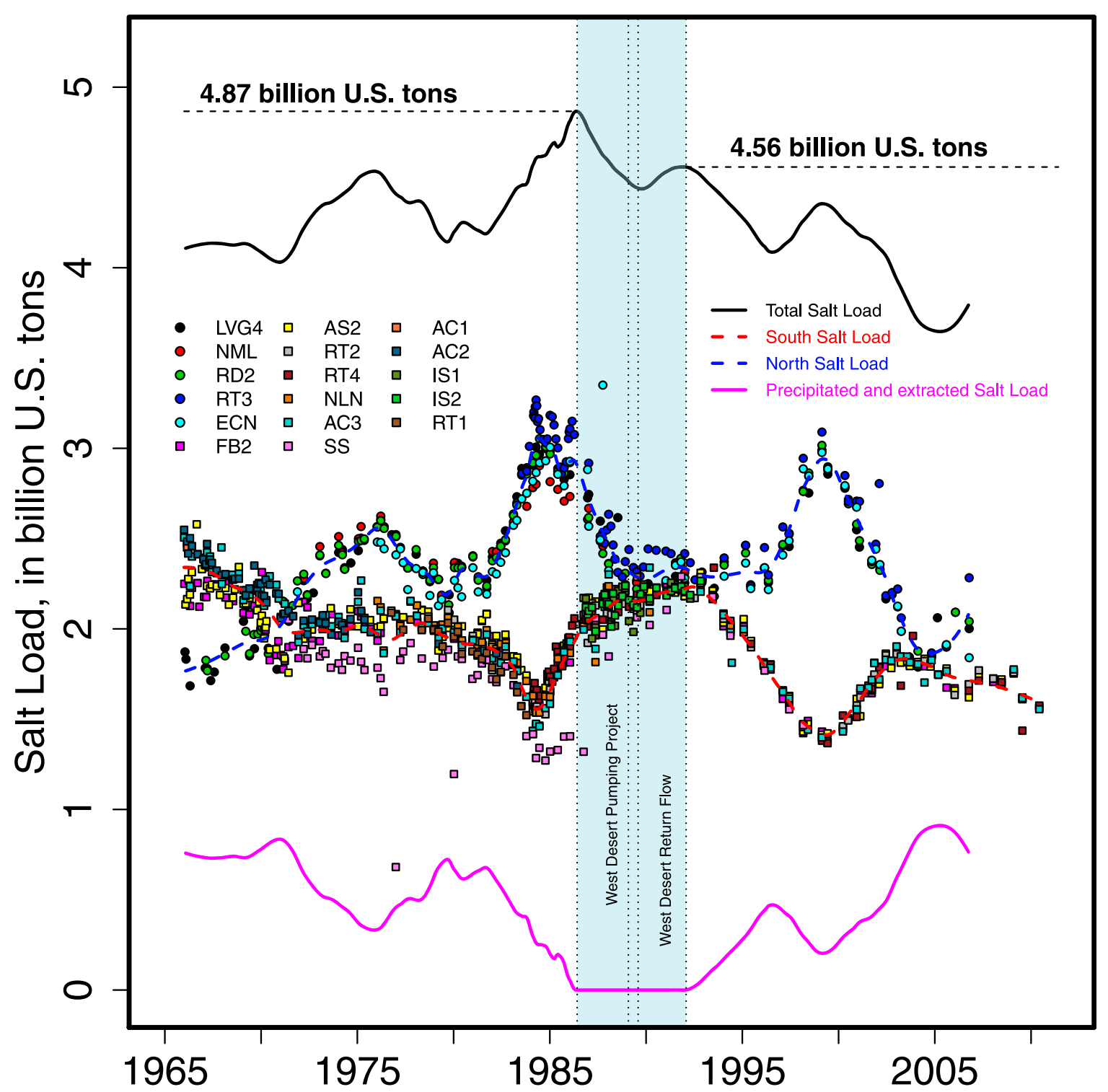

Figure 8. GSL total salt load calculated from volume- and depth-averaged measurements. Data obtained from E. Gaddis (unpublished data, 2011). Loads here are reported in U.S., or short, tons. (1 U.S. ton = 0.9072 metric tons.)

[27] A water balance for the lake can be expressed as

$$
\frac{\Delta V}{\Delta t}=P \cdot A+Q-E \cdot A-P u m p+R
$$

where $P$ is precipitation directly on the lake, $Q$ is flow entering the lake, $A$ is lake area, $E$ is per unit area evaporation rate from the lake, Pump is pumping from the lake into the west desert and $R$ is return water to the lake from west desert pumping. $Q$ includes predominantly streamflow but also a small component of groundwater. The variables Pump and $R$ are zero most of the time but have been included here in order to account for the manipulations to the GSL level caused by the West Desert pumping project in 1987-1989 and the return flow to the GSL in 1990-1992. Recorded lake levels were used with bathymetry to evaluate lake volume changes and area each month. We used observations of
$P, Q$, Pump and $R$ to infer historic evaporation volume and depth using a rearrangement of equation (8). Evaporation calculated this way is referred to as mass balance evaporation.

[28] Evaporation from the GSL is sensitive to salinity, which controls the saturation vapor pressure above the lake's surface. Salinity decreases as volume increases and vice versa. Stumm and Morgan [1981] defined the activity coefficient, $\beta$, of water with salinity, $C$, as the ratio of vapor pressure over salt water to vapor pressure over fresh water at the same temperature. This activity coefficient of water $\beta$ in a solution of known chemical composition can be calculated using a composite reduction factor obtained by summing the weighted reduction in saturation vapor pressure due to each of the constituent salt ions. Mohammed [2006] suggested that the evaporation from the GSL can be estimated from the following modification to the Penman equation, which adjusts for the saturation vapor pressure 


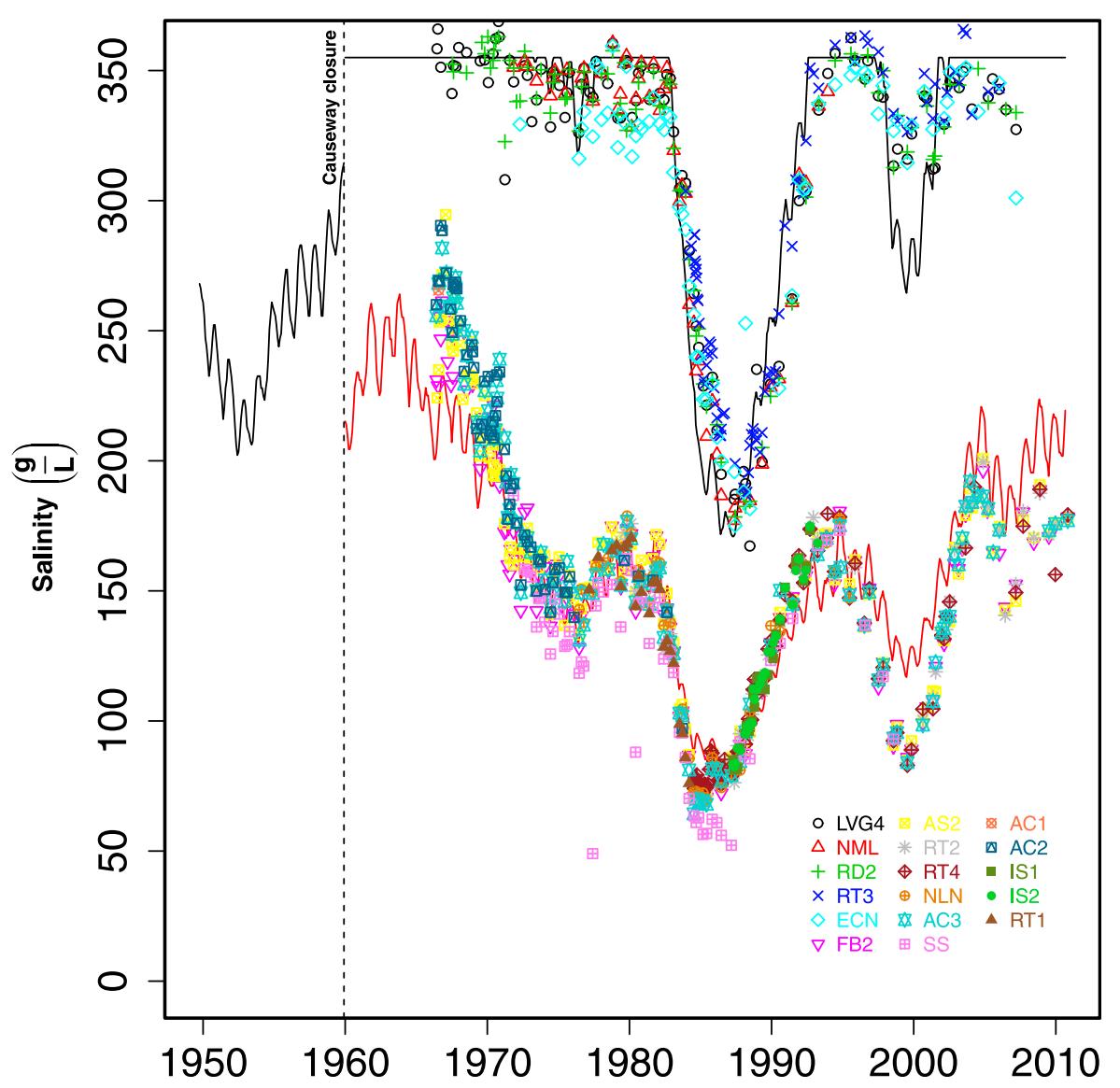

Figure 9. Salinity computed from $C=L / V$ for each arm (lines) compared to observations at stations.

above a saline surface being less than the saturation vapor pressure above fresh water at the same temperature:

$$
E_{s a l}=\frac{\Delta^{\prime}}{\Delta^{\prime}+\gamma} \cdot \frac{R_{n}}{\lambda_{v} \rho_{w}}+\frac{\gamma}{\Delta^{\prime}+\gamma} \cdot K_{E} \nu_{a}\left(e_{s}\left(T_{a}\right) \beta\left(T_{a}, C\right)-e_{a}\right)
$$

where $E_{\text {sal }}$ is evaporation from a saline surface $\left(\mathrm{m} \mathrm{d}^{-1}\right)$. $\Delta^{\prime}$ is the gradient of the saturated vapor pressure for a saline surface $\left(\mathrm{kPa}^{\circ} \mathrm{C}^{-1}\right), \gamma$ is the psychometric constant equal to $\frac{c_{a} \cdot P}{0.622 \lambda_{v}}\left(\mathrm{kPa}^{\circ} \mathrm{C}^{-1}\right), P$ is atmospheric pressure $(\mathrm{kPa})$, $c_{a}$ is the heat capacity of air $\left(1.00 \times 10^{-3} \mathrm{MJ} \mathrm{kg}^{-1}{ }^{\circ} \mathrm{C}^{-1}\right)$, $\lambda_{v}$ is the latent heat of vaporization $\left(2.5-2.36 \times 10^{-3} T\right.$, in $\left.\mathrm{MJ} \mathrm{kg}{ }^{-1}\right), T$ is air temperature $\left({ }^{\circ} \mathrm{C}\right), \rho_{w}$ is the water density $\left(\mathrm{kg} \mathrm{m}^{-3}\right)$ and $K_{E}$ is the bulk latent heat transfer coefficient $\left(\mathrm{kPa}^{-1}\right) . R_{n}$ is the net energy available at the water surface (MJ m $\left.{ }^{-2} \mathrm{~d}^{-1}\right), \nu_{a}$ is the wind speed over the surface $\left(\mathrm{m} \mathrm{d}^{-1}\right), e_{s}\left(T_{a}\right)$ is the saturation vapor pressure of a freshwater surface at air temperature $(\mathrm{kPa}), e_{a}$ is the vapor pressure of the air $(\mathrm{kPa})$, and $T_{a}$ is air temperature $\left({ }^{\circ} \mathrm{C}\right) . \beta$ is the water activity coefficient and $C$ is the brine concentration $\left(\mathrm{g} \mathrm{L}^{-1}\right)$.

[29] Equation (9), with monthly climate inputs, was used to calculate climate driven evaporation based on lake salinity $C$ from equations (6) and (7). $e_{a}$ was determined from dew point temperature and $T_{a}$ was the average of monthly maximum and minimum temperatures. Daily wind speed data was averaged to months. Separate north and south arm climatedriven evaporation values were computed and evaporation from the lake as a whole was calculated by area weighted averaging of these values. We also calculated the climate driven evaporation for freshwater conditions by setting $C=0$. Figure 10 compares these climate driven evaporation estimates with evaporation calculated from mass balance. Figure 10 shows the degree to which salinity depresses evaporation as compared to freshwater evaporation for the same conditions. Figure 10 also shows that, in general, saline evaporation calculated from monthly climate inputs is slightly higher than the evaporation calculated using mass balance. Note the greater degree of variability of mass balance evaporation estimates, which reflects, to some degree, a greater uncertainty in the mass balance estimates. The mass balance evaporation estimate is a closure quantity that absorbs errors and omissions. The difference between climate and mass balance evaporation of about $0.1 \mathrm{~m} \mathrm{yr}^{-1}$ corresponds to a volume of approximately $0.38 \mathrm{~km}^{3} \mathrm{yr}^{-1}$, which is about $9 \%$ of the total GSL inputs. This difference may reflect unquantified inflows or uncertainty and bias in the evaporation calculations, noting that the Penman equation may not fully or properly account for the apportioning of available energy into heat absorbed by the lake and the averaging of nonlinearities when applied at a monthly scale. There may also be bias due to the use of average salinity rather than surface salinity in evaporation calculations, but due to higher brine concentrations at depth, surface salinity is likely lower than average salinity and would tend to increase climate-based evaporation estimates increasing the difference between climate and mass balance evaporation estimates. This difference 


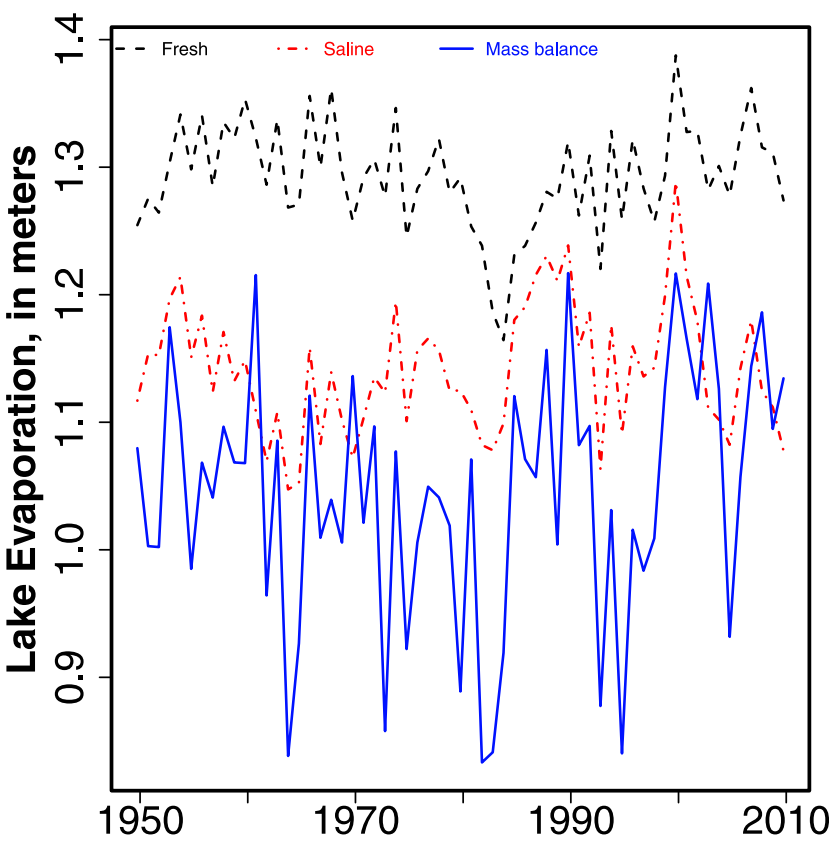

Figure 10. The Great Salt Lake's annual evaporation. Total lake evaporation calculated from mass balance, climate based on salinity, and climate based on freshwater conditions.

between climate and mass balance evaporation will carry through to the results that use evaporation calculated from climate inputs and result in lower predicted lake levels.

\section{Great Salt Lake Sensitivity}

[30] Equation (8) states that changes in precipitation on the lake, streamflow input to the lake and evaporation from the lake produce changes in the lake volume. In other words, lake volume changes are sensitive to changes in precipitation, streamflow and evaporation. Evaporation and precipitation are also modulated by lake area, which varies in response to the system dynamics involving the bathymetry relationships between volume, area and level [Mohammed and Tarboton, 2011]. Two questions then arise: is lake volume change equally sensitive to precipitation, streamflow and evaporation or not and which variable among precipitation, streamflow or evaporation could influence the lake volume the most? In response to these questions, we drew upon the concept of elasticity [Schaake, 1990; Sankarasubramanian et al., 2001;
Fu et al., 2007b] to quantify sensitivity of changes in lake volume to input changes. The quantity that we are interested in understanding is change in volume, rather than volume per se, and the change in volume may be 0 , positive or negative. Therefore, rather than using quantities $d V / V, d Q / Q, d P / P$ as in equation (1), we quantify the sensitivity of lake volume change by evaluating the ratio of standard deviation of these variables (precipitation, streamflow and evaporation) to the standard deviation of the lake volume change. This can be expressed as: $\phi_{P}=\frac{\sigma_{P}}{\sigma_{\Delta V}}, \phi_{Q}=\frac{\sigma_{Q}}{\sigma_{\Delta V}}$ and $\phi_{E}=\frac{\sigma_{E}}{\sigma_{\Delta V}}$, where $\phi_{P}$ is precipitation sensitivity, $\phi_{Q}$ is streamflow sensitivity and $\phi_{E}$ is evaporation sensitivity. The units for precipitation, evaporation and streamflow are volume units and the time scale is annual. In Table 2, we present these sensitivity estimates based on 61 years of historic data for the GSL (19502010). In Table $2 \Delta V$ is change in lake volume $\left(\mathrm{km}^{3}\right), Q$ is annual streamflow input to the lake, $P_{v}$ is volumetric precipitation on the lake, $P$ is depth precipitation on the lake, $E_{v}$ is saline volumetric evaporation from the lake, $E f_{v}$ is fresh volumetric evaporation from the lake, $E$ is depth saline evaporation from the lake, $E f$ is depth fresh evaporation from the lake, $A$ is lake area and $S C F$ is an evaporation salinity correction factor calculated as $S C F=E / E f$. $\mu$ is arithmetic mean, $\sigma$ is standard deviation, $C V$ is coefficient of variation of each quantity, $\rho$ is correlation with change in lake volume and $\phi$ is the sensitivity index scaled as indicated in the formula column ( $\phi$ formula). Table 2 also includes the sensitivity measures for lake area, $A$, with separately evaluated sensitivities associated with precipitation and evaporation expressed as depth quantities; the sensitivity to climate calculated freshwater evaporation (potential evaporation); and the salinity correction factor. In our calculations, we scaled these sensitivities by appropriate average quantities, as presented in the column ( $\phi$ formula) in Table 2 , in order to make the ratio dimensionless. Precipitation and evaporation quantities expressed as depth standard deviation, $\sigma(P), \sigma(E)$ and $\sigma(E f)$, were multiplied by average lake area to make them dimensionally equivalent to volume change standard deviation. For the sensitivity to lake area, $A$, we present results for both options of scaling, i.e., scaling was used with average precipitation and average evaporation depths. Both of average precipitation and average evaporation depths are modulated by lake area. For the salinity correction factor (SCF) sensitivity, we multiply it by average lake area and freshwater evaporation depth since SCF acts on volume through the freshwater evaporation and lake area. We also

Table 2. Great Salt Lake Sensitivity Analysis Based on Annual Data From 1950 to 2010

\begin{tabular}{|c|c|c|c|c|c|c|}
\hline Variable & $\mu$ & $\sigma$ & $C V$ & $\rho$ & $\phi$ & $\phi$ Formula \\
\hline$\Delta V\left(\mathrm{~km}^{3}\right)$ & & 1.86 & & & & \\
\hline$Q\left(\mathrm{~km}^{3}\right)$ & 2.84 & 1.54 & 0.54 & 0.86 & 0.83 & $\sigma(Q) / \sigma(\Delta V)$ \\
\hline$P_{v}\left(\mathrm{~km}^{3}\right)$ & 1.07 & 0.41 & 0.38 & 0.61 & 0.22 & $\sigma\left(P_{v}\right) / \sigma(\Delta V)$ \\
\hline$P(\mathrm{~m})$ & 0.53 & 0.15 & 0.29 & 0.73 & 0.30 & $\sigma(P) / \sigma(\Delta V) \times \bar{A}$ \\
\hline$E_{v}\left(\mathrm{~km}^{3}\right)$ & 4.40 & 1.03 & 0.23 & -0.07 & 0.55 & $\sigma\left(E_{v}\right) / \sigma(\Delta V)$ \\
\hline$E f_{v}\left(\mathrm{~km}^{3}\right)$ & 4.94 & 0.95 & 0.19 & -0.06 & 0.51 & $\sigma\left(E f_{v}\right) / \sigma(\Delta V)$ \\
\hline$E(\mathrm{~m})$ & 1.14 & 0.05 & 0.04 & -0.51 & 0.10 & $\sigma(E) / \sigma(\Delta V) \times \bar{A}$ \\
\hline$E f(\mathrm{~m})$ & 1.29 & 0.04 & 0.03 & -0.56 & 0.07 & $\sigma(E f) / \sigma(\Delta V) \times \bar{A}$ \\
\hline$A\left(\mathrm{~km}^{2}\right)$ & 3656.02 & 792.00 & 0.22 & -0.15 & $\begin{array}{l}0.23 \\
0.49\end{array}$ & $\begin{array}{l}\sigma(A) / \sigma(\Delta V) \times \bar{P} \\
\sigma(A) / \sigma(\Delta V) \times \bar{E}\end{array}$ \\
\hline$S C F$ & 0.88 & 0.04 & 0.04 & -0.08 & 0.09 & $\sigma(S C F) / \sigma(\Delta V) \times \bar{A} \times \bar{E} f$ \\
\hline
\end{tabular}


report arithmetic mean $(\mu)$, unbiased standard deviation $(\sigma)$, coefficient of variation $(C V=\sigma / \mu)$ and correlation $(\rho)$ of each variable with change in lake volume. The statistics $\mu, C V, \rho$ and $\phi$ are not reported for $\Delta V$ because the mean of $\Delta V$ is theoretically 0 , so $C V$ is undefined and $\rho$ and $\phi$ are being evaluated with respect to $\Delta V$. The evaporation variables $\left(E, E_{v}\right)$ were determined from climate and salinity as shown in equation (9), while $E f$ and $E f_{v}$ were determined from only climate, i.e., assuming no salinity $(C=0)$.

[31] Examining the GSL volume change sensitivity values in relation to variables studied in Table 2, we see that streamflow fluctuations have the highest sensitivity value (0.83) with volume change. This is consistent with the high correlation $(\rho=0.86)$ between streamflow and volume change at an annual scale. In addition, streamflow input to the lake has the highest variability $(C V=0.54)$. This indicates that streamflow fluctuations dominate the GSL volume change sensitivity. The variable with second highest sensitivity $(\phi=0.55)$ is evaporation volume (or $\phi=0.51$ when evaluated as fresh evaporation). However, the correlation of evaporation volume $\left(E_{v}\right)$ with changes in lake volume is weak $(\rho=-0.07)$. On the other hand the sensitivity to evaporation depth is small $(0.1)$, while the correlation of evaporation depth $(E)$ with lake volume changes is high in a negative sense $(\rho=-0.51)$. The obvious question is then why lake volume changes are highly correlated with evaporation depth $(E)$ but not correlated with evaporation volume $\left(E_{v}\right)$, while sensitivities to lake volume change are larger for evaporation volume than depth. Our interpretation has to do with time scales. Variability in evaporation volume, which is the product of evaporation depth and lake area, is dominated by fluctuations in lake area which occur over scales of 5 to 20 years and even longer. When the volume is larger, the surface area is larger and evaporation is greater. This is a negative feedback or stabilizing effect. This area effect on modulating evaporation is an important process in the overall sensitivity of lake volume changes and it is dominated by longer time scales. This area effect is also seen in the sensitivity to area variability when scaled relative to evaporation $(\phi=0.49)$. The negative correlation of area with volume change is consistent with its stabilizing role. The stabilizing effect of area changes appears to be more than the stabilizing effect associated with salinity. Increases in lake volume reduce salinity, which leads to increases in evaporation, another stabilizing effect, but Table 2 gives $\phi=0.09$ for $S C F$, indicating that this salinity effect is less. On the other hand, at shorter time scales, year to year fluctuations in climate driven evaporation and precipitation are best quantified by evaporation and precipitation depth quantities that avoid the confounding effects of large lake area changes over long time scales. Thus, we see in Table 2 that $P, E$ and $E f$ correlate well with year to year lake volume change but play a lesser role in overall sensitivity.

[32] Precipitation (as depth) over the lake has a sensitivity value of 0.30 . Precipitation is also highly correlated with changes in lake volume $(\rho=0.73)$. We think that this correlation overstates the sensitivity of direct precipitation on the lake because lake precipitation is highly correlated with precipitation in the watersheds, which drives streamflow draining to the lake, whereas the sensitivity index more correctly quantifies the relative importance of precipitation variability as a driver of lake volume changes. The sensitivity to area variability when scaled by precipitation is 0.23 , indicating some relatively small sensitivity associated with the interaction of lake area and precipitation volume. The GSL volume change sensitivity to salinity correction factor is small, with a value of 0.09. Similarly, the differences between fresh and saline evaporation sensitivities are small, indicating the relatively minor role of salinity in comparison to streamflow, precipitation and lake area in the sensitivity of overall lake volume.

[33] We can thus summarize the GSL volume change sensitivity analysis by saying that it is dominated by fluctuations in streamflow input to the lake and the stabilizing effect of lake area. Climate conditions over the lake play a lesser role, with precipitation having greater sensitivity than evaporation depth overall. These interpretations are based on the range of historic variability. While these are helpful in understanding the behavior of the lake and the relative dominance of the interacting processes, they do not directly quantify the sensitivity to shifts in the mean of input quantities. Section 5 uses a mass balance model to quantify sensitivity to shifts in input quantities.

\section{Great Salt Lake Mass Balance Model}

[34] We have developed a model, the Great Salt Lake Mass Balance Model (GSLMBM), to track lake volume, level, area and salinity based on equations (7)-(9). The purpose of the model is to evaluate the sensitivity of GSL levels in the future to changes in streamflow or climate inputs. The model is driven by inputs: precipitation on the lake, streamflow and groundwater draining to the lake and evaporation from the Lake's surface based on climate and salinity conditions. Equation (8) is used to evaluate the change in lake volume, which then affects salinity (equation (7)), level and area. Evaporation is calculated from climate inputs, area and salinity (equation (9)). Monthly time steps are used. For predictive runs, the model also incorporated a setting that triggered activation of the west desert pumping project when the GSL level reached $1282.6 \mathrm{~m}$ (4208 feet) to protect infrastructure. Volumes of the lake in excess of this level are assumed to be pumped into the west desert evaporation ponds, effectively capping the lake at this level.

[35] The model was validated by comparing its output to historic lake level values from October 1949 to September 2010 when driven by historic inputs. The lake level on 1 October 1949 of $1279.1 \mathrm{~m}$ (4196.7 feet) was used to initialize the GSLMBM. Historical monthly inputs of precipitation, streamflow, wind speed and air temperature from 1949 to 2010 , as well as historic pumping to the west desert, were used to drive the model. The comparison of observed lake level (average of both arms weighted by area) and modeled lake level over this historic period indicates the general ability of the model to track lake levels (Figure 11). This is a 61 year model run driven only by inputs; the only observed lake level used was the initial condition. The degree of correspondence reflects the soundness of the model and the stabilizing effect of the lake's physical behavior in response to inputs. The lake area and volume adjust so that outputs balance inputs over the long term and the model captures this effect. The model explains about $81 \%$ of the variability seen in GSL level as quantified by the Nash-Sutcliffe 


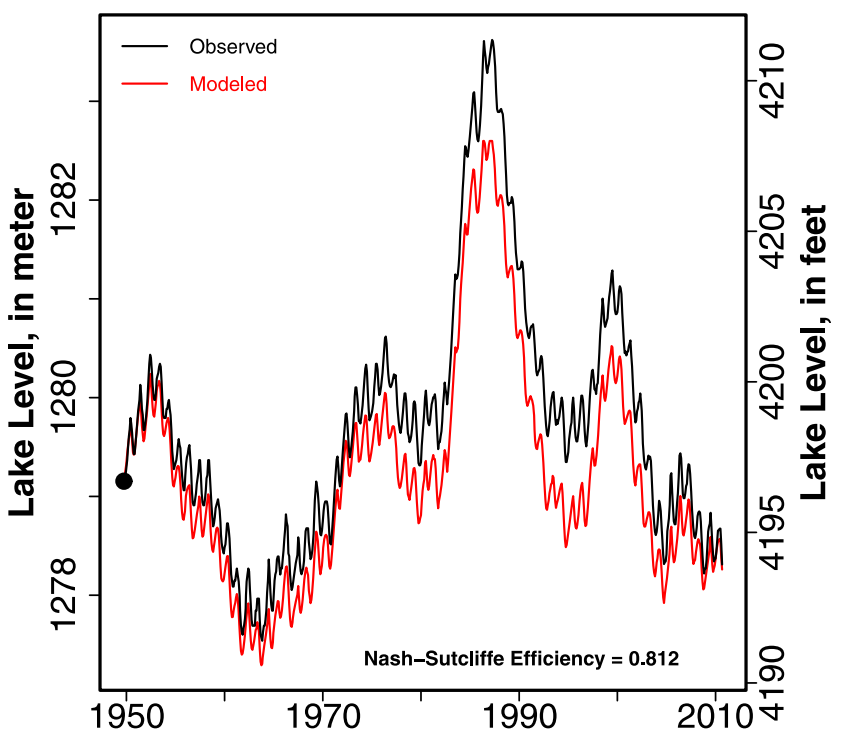

Figure 11. Observed and modeled monthly Great Salt Lake level. Modeled monthly Great Salt Lake levels were initialized on 1 October 1949.

efficiency measure [Nash and Sutcliffe, 1970]. Note, however, that modeled lake levels are consistently lower than observed levels. This is due to the evaporation bias seen in Figure 10. Future predictions of GSL levels using this model will need to be interpreted recognizing the presence of this bias.

[36] The autocorrelation function (ACF) of total annual inputs (1950-2010) to the GSL indicates significant annual correlation with decay in correlation to near zero after about 4 years (Figure 12). We used the $k$-nearest-neighbor method [Lall and Sharma, 1996] to generate representative realizations of future climate and streamflow inputs to drive the model and reproduce this autocorrelation. We used block sampling at the annual scale based on total annual input to the lake. This involved identifying, for each simulation year, $k$ years from the historic record with total previous year annual input close to the annual input of the previous simulation year, then picking one of these at random using the $k$-nn kernel. All inputs (precipitation, streamflow and temperature for all months) from the historic year selected are taken as simulation inputs for the current year. Figure 12 shows box plots of ACF from 100 realizations of total annual inputs simulated this way, in comparison to the historic ACF. Note that the range of variability in the simulations encompasses the historic ACF well, indicating that this approach satisfactorily reproduces the historic ACF. This block resampling of all inputs by year retains the statistical dependence among monthly inputs (except across years) and among different inputs (precipitation, temperature, streamflow) in a natural and simple way.

[37] The average streamflow input to the GSL over the last 5 years (2005-2010) was about 25\% less than the average streamflow input to the GSL over the full record (1950-2010), indicating that, at a time scale comparable to the time scales of the GSL fluctuation, variability in streamflow on the order of $25 \%$ is plausible. On this basis we evaluated the sensitivity of the GSL to changes in streamflow inputs by generating simulations where annual streamflow input to the lake was altered $\pm 25 \%$.

[38] The North American Regional Climate Change Assessment Program (NARCCAP) future estimates for air

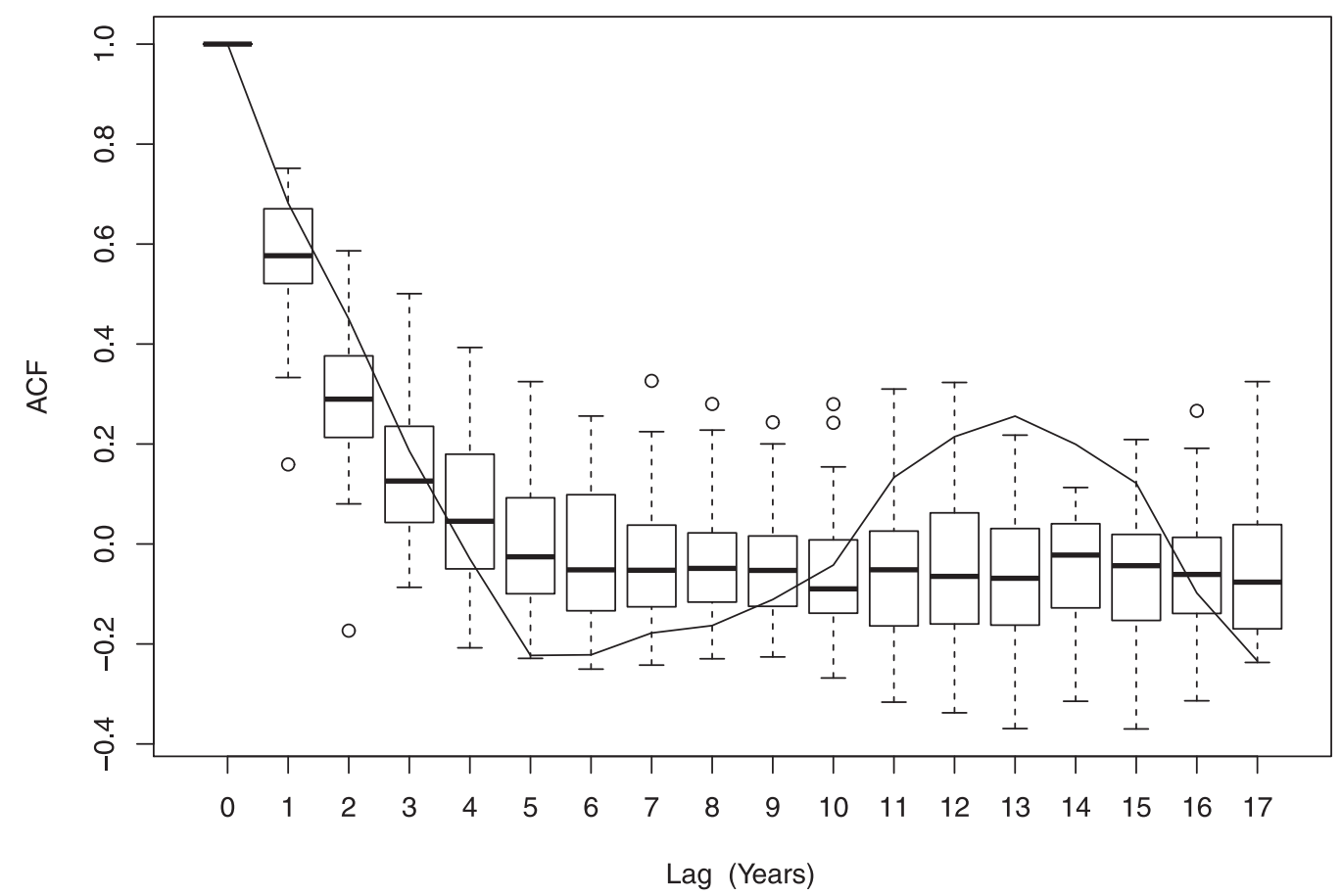

Figure 12. Autocorrelation (ACF) box plots of the total annual inputs to the Great Salt Lake using the $k$-nn method. The line gives the ACF of the historical total annual inputs to the GSL (1950-2010). 
temperature over the GSL area suggest that air temperature might increase in the ranges of $3^{\circ} \mathrm{C}$ to $4^{\circ} \mathrm{C}$ [Mearns et al., $2007,2009]$. On this basis, we used a climate change scenario that comprised a $4.0^{\circ} \mathrm{C}$ increase in air temperature and dew point to evaluate the sensitivity of the GSL to potential future warming.

[39] An ensemble of 100 sequences, each consisting of 30 years drawn from the 61 years of historic streamflow, precipitation and evaporation was generated using the $k$-nearest-neighbor resampling method and was used to drive the GSLMBM for the lake as it currently is. Predictions were initialized using lake levels recorded on 1 October 2010. In these simulations, the climate driven evaporation calculated from temperature, wind and salinity was used. We examined the sensitivity of future predicted lake levels by assuming that either streamflow input to the GSL or air temperature over the lake (evaporation) would change. Figure 13 examines the sensitivity of GSL level predictions over the 30 year period to streamflow for three scenarios: resampling from historic inputs; $25 \%$ decrease applied to resampled historic inputs; and $25 \%$ increase applied to resampled historic inputs. The three lines give median lake level across the ensemble for each scenario. We also depict ranges by showing colored shaded areas that depict the interquartile range between the 25th and 75 th percentiles for the $\pm 25 \%$ streamflow scenarios. Our prediction results suggest that changes in streamflow input to the lake would significantly influence lake level in about 5 years and that lake level would stabilize around a new median in about 15 years. For example after 5 years, a $25 \%$ increase in streamflow input to the GSL would increase the lake level by about $55 \mathrm{~cm}$ (1.8 feet) on average, while a $25 \%$ decrease in streamflow input to the lake would reduce the lake level by about $66 \mathrm{~cm}$ ( $2.2 \mathrm{feet})$ on average.

[40] The stabilization of lake level around a new median in about 15 years is due primarily to the negative feedback effect caused by the adjustment of lake area consistent with the area sensitivity discussed above.

[41] The same ensemble of 100 sequences of 30 years each that was used for streamflow was also used to examine the sensitivity to a potential $4.0^{\circ} \mathrm{C}$ warming. The results indicate the degree to which lake level is lowered due to simulated increase in evaporation. After 5 years, a $4.0^{\circ} \mathrm{C}$ increase in air temperature would reduce the lake level by about $34 \mathrm{~cm}$ (1.1 feet) on average in comparison with lake level conditions with no change in air temperature (Figure 14). The two lines show lake level median predictions for no air temperature change and a $4.0^{\circ} \mathrm{C}$ increase. We also depict lake level ranges by showing the interquartile range for the warming scenario as a colored shaded area. We note here that lake level prediction under different air temperatures scenarios also stabilize in about 15 years. This examination of the sensitivity of GSL levels to changes in air temperature increases our understanding of how the lake would respond to potential future climate warming.

\section{Discussion and Conclusions}

[42] This work has used analysis of historic data and modeling to identify the sensitivities of Great Salt Lake volume to inputs and to factors internal to the dynamics of the system. We found that changes in lake volume are most sensitive to fluctuations in streamflow input, with sensitivity as quantified by the ratio of variabilities, $\phi_{Q}=\sigma_{Q} / \sigma_{\Delta V}$, of 0.83 . The indices quantifying sensitivity to changes in evaporation from the lake, fluctuation of lake area, precipitation acting on the lake and lake salinity conditions have values of $0.55,0.49,0.30$ and 0.09 , respectively. These variables constitute the most influential system drivers and factors with respect to GSL volume changes. Quantification of these GSL volume change sensitivities has given us a more comprehensive understanding the roles of the different variables acting on the GSL system. This is important

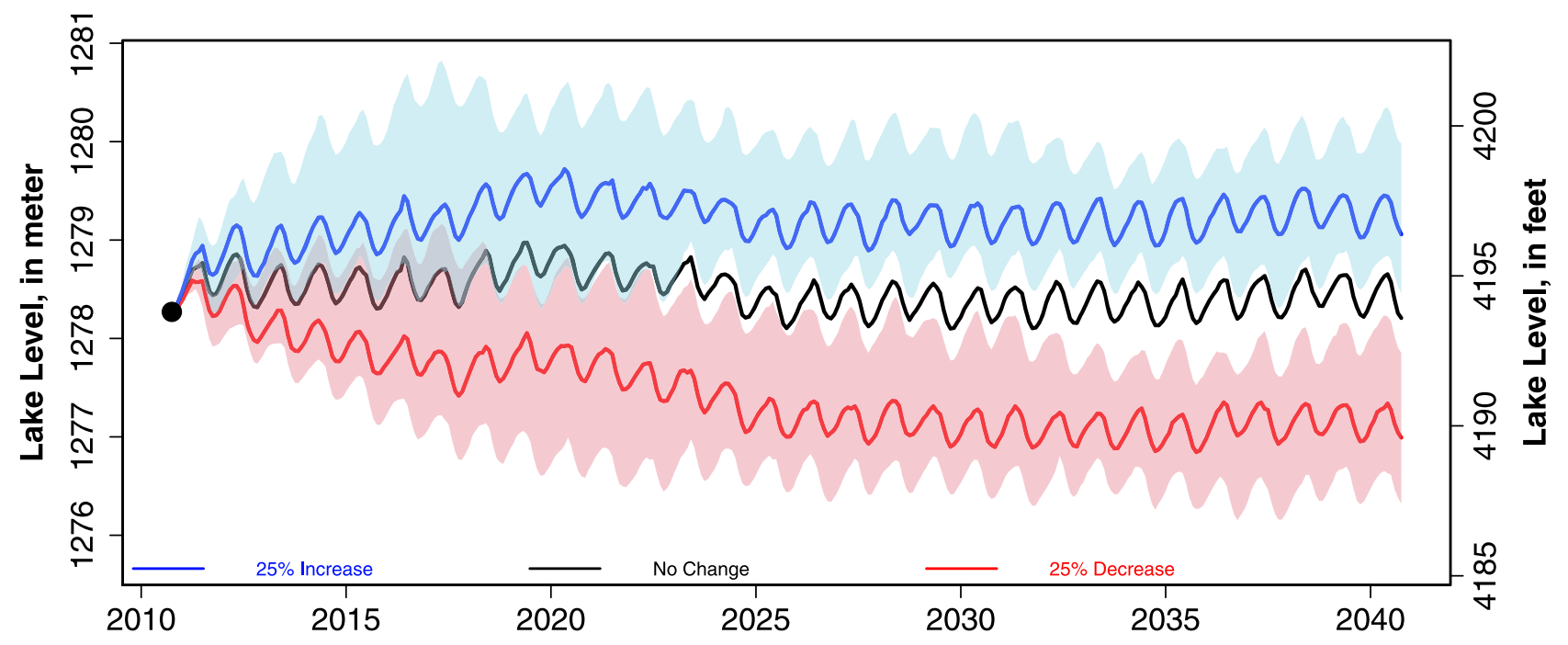

Figure 13. Great Salt Lake level predictions time series under different streamflow input change scenarios $(25 \%$ decrease from annual streamflow input, no streamflow input changes, and $25 \%$ increase from annual streamflow input). Shaded colored areas give the 25 th and 75 th percentiles for lake level predictions under streamflow changes. Lines give the median (50th percentile) lake level predictions. 


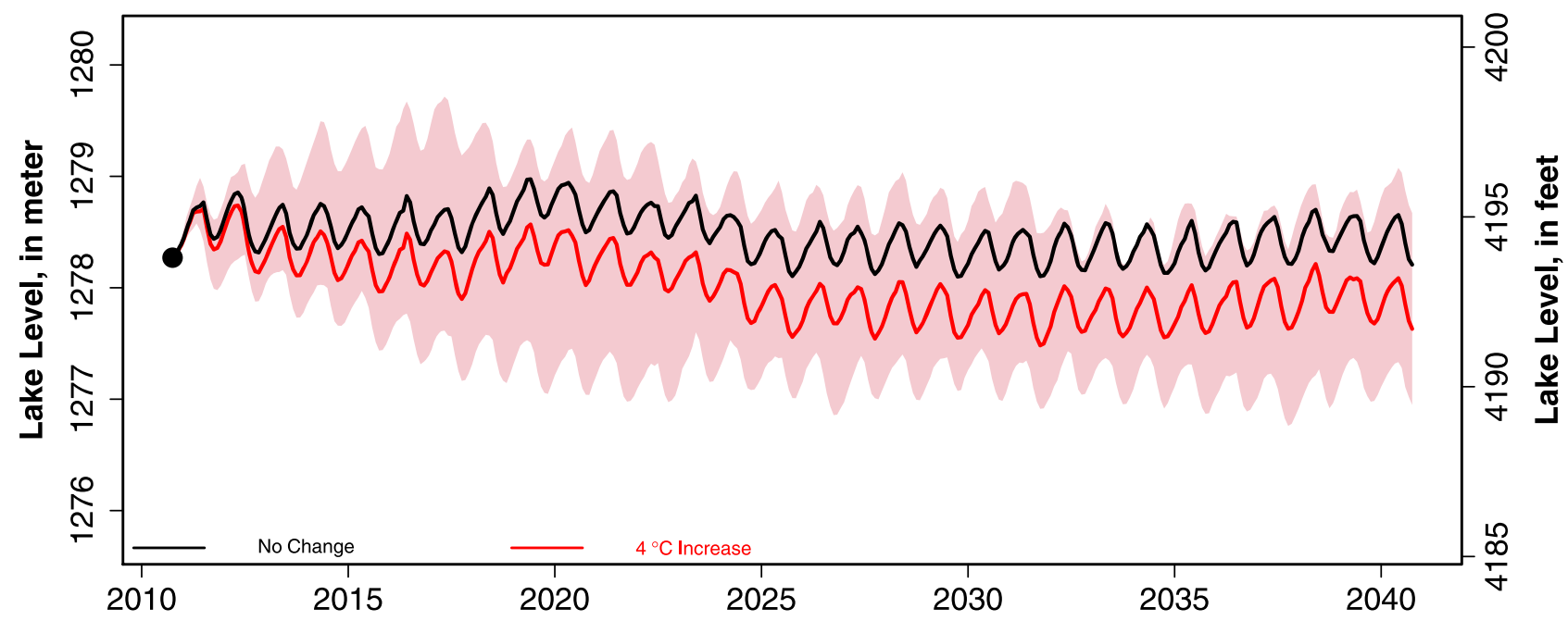

Figure 14. Great Salt Lake level prediction time series under air temperature input change scenario of a $4.0^{\circ} \mathrm{C}$ increase from average monthly air temperatures. The shaded colored area spans the 25 th to 75 th percentiles for the warming scenario. Lines give the median (50th percentile) lake level predictions.

in support of robust decision making that addresses multiple GSL management issues.

[43] This work has also developed a physically based mass balance model (GSLMBM) that forecasts the GSL levels for different input scenarios. The GSLMBM includes a physical evaporation component that accounts for salinity. Climate and streamflow inputs, generated using the $k$-nearest-neighbor method [Lall and Sharma, 1996], drove the GSLMBM. This enabled the evaluation of sensitivity within the context of the natural range of variability and the dependence structure of the inputs. The results provide a distribution of possible lake levels for any time in the future. The differences between these distributions for different input scenarios quantify the sensitivity of lake level to streamflow and climate changes.

[44] Consistent with the greater sensitivity to streamflow inferred from the elasticity sensitivity index, we find from the dynamic simulations that the lake has a greater sensitivity to streamflow changes than to the $4^{\circ} \mathrm{C}$ warming change. The results also show that the range of variability remains as big as or bigger than the predicted changes in median and that the entire distribution shifts with the median.

[45] Several factors interact and affect evaporation from the GSL. These include lake area, salinity and weather conditions. In evaluating lake sensitivity, we used adjusted Penman evaporation calculations because they are physically based, which makes them responsive to the climate (temperature) change inputs we wanted to evaluate. This is best for evaluating differences in a relative sense, but absolute values of predictions are subject to the difference/bias we noted between mass balance and adjusted Penman evaporation calculations, both of which have uncertainty as discussed above. These uncertainties suggest that it would be valuable to measure evaporation from the lake directly (e.g., using Eddy covariance) to bring better resolution to the noted difference.

[46] In summary, this paper addresses the sensitivity of GSL volume changes to watershed management, climate and salinity. This quantification of the GSL volume change sensitivity to variables and factors related to the lake is part of our effort to understand the GSL dynamics and the different impacts associated with watershed changes, along with anthropogenic use of lake resources (withdrawals for mineral extraction). The results have clarified the contribution of different variables that dynamically interact in the GSL system toward overall system sensitivity, and the model provides a tool for quantitatively evaluating the sensitivity of the GSL to future inputs in the context of the range of variability arising due to the stochastic nature of the driving inputs.

\section{Appendix A: Great Salt Lake Surface Water Inflow}

[47] Three major rivers, the Bear, Weber and Jordan Rivers, flow into the GSL. The Bear River has been gauged since 1902, the Weber River since 1907 and the Jordan since 1949. The specific stations where streamflow data are available have changed over the years. A detailed study of streamflow inputs to the GSL from the Bear River, the Weber River, the Jordan River, as well as other minor streams, was conducted by Loving et al. [2000] who estimated the GSL streamflow inputs for 12 years from 1987-1998. Loving et al. [2000] present regression equations for estimating streamflow at locations where streamflow data is missing. We followed these regressions as closely as possible to compile the monthly streamflow inputs for the period 1 October 1949 to 30 September 2010. However, we did need to extend these methods to be able to estimate streamflow into the GSL for the extended period. Where streamflow data was missing, it was estimated using regression with a nearby station, preferably upstream in the same basin, or where correlation was best. Streamflow gaging stations used to estimate monthly surface water inflow to the Great Salt Lake are given in Table A1. 




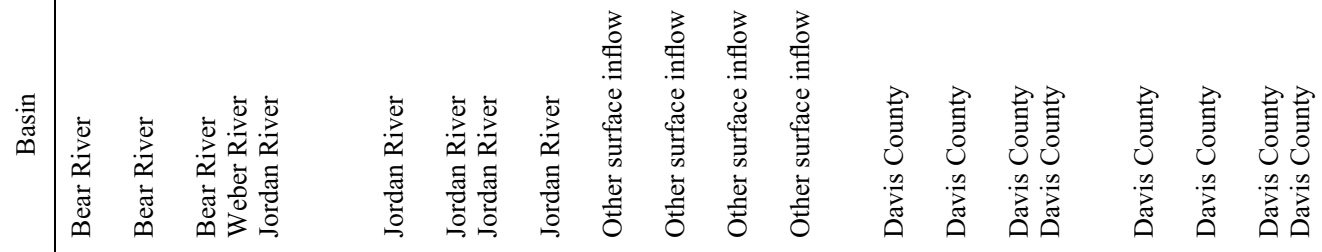

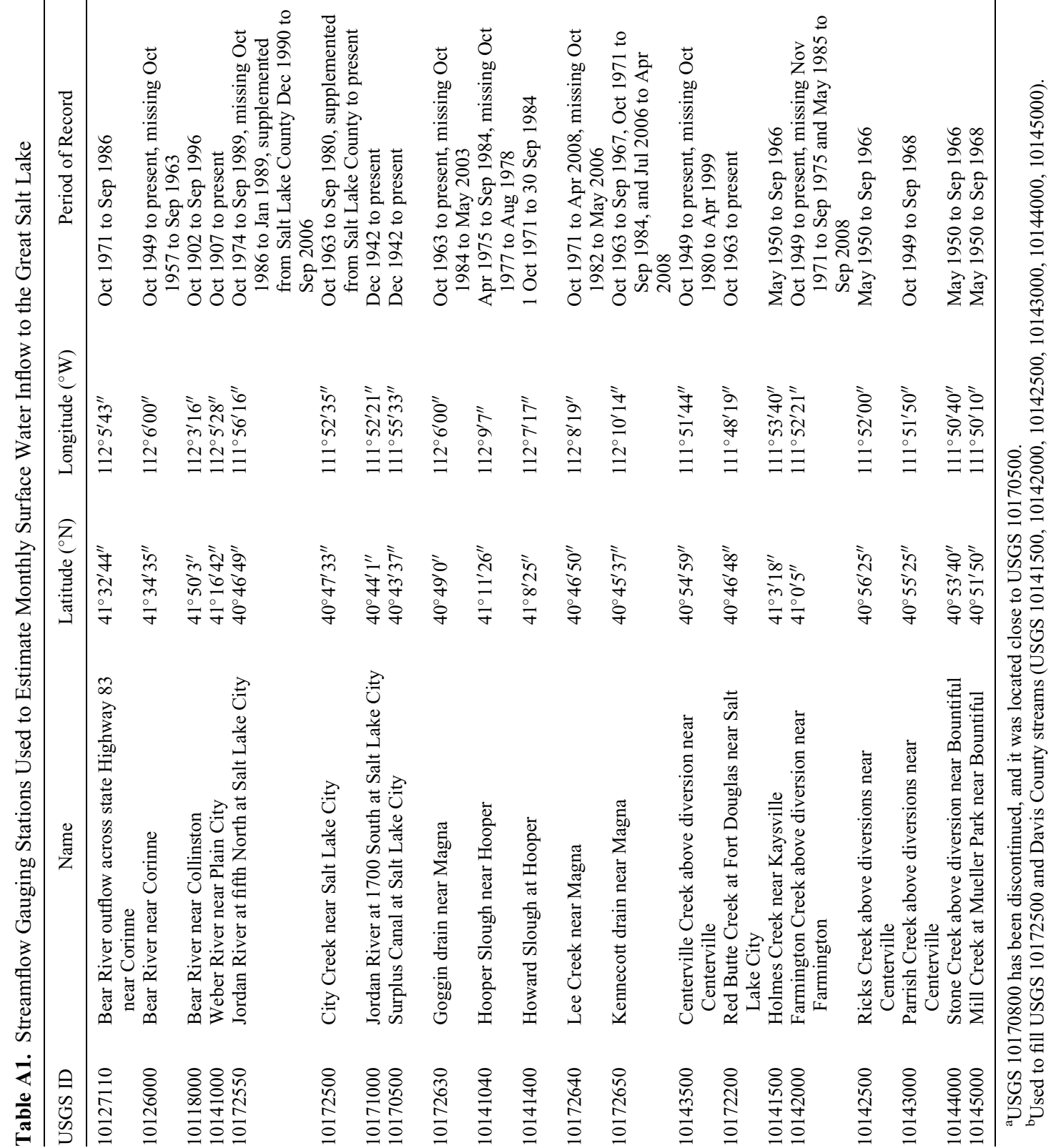


Table A2. Regression Estimates of Monthly Surface Water Inflow to the Great Salt Lake (1950-2010) ${ }^{\mathrm{a}}$

\begin{tabular}{|c|c|c|c|c|c|c|c|c|}
\hline Basin & $\begin{array}{l}\text { Site Estimated } \\
\text { (Dependent } \\
\text { Variable) }\end{array}$ & $\begin{array}{c}\text { Site Measured } \\
\text { (Independent } \\
\text { Variable) }\end{array}$ & Period of Regression & A (Slope) & B (Intercept) & $\mathrm{R}^{2}$ & $\begin{array}{l}\text { Months for } \\
\text { Which } \\
\text { Regression } \\
\text { Is Valid }\end{array}$ & Units \\
\hline \multirow[t]{2}{*}{ Bear River } & 10126000 & 10118000 & Oct 1957 to Sep 1963 & 1.039 & 7150 & 0.995 & all months & acre-feet/month \\
\hline & 10127110 & 10126000 & 1972 to 1986 & 1.007 & 14,264 & 0.999 & all months & acre-feet/month \\
\hline \multirow[t]{7}{*}{ Jordan River } & 10172550 & $\begin{array}{c}10171000 \\
+10172500\end{array}$ & Oct 1974 to Sep 1986 & 1.0897 & 4695 & 0.553 & all months & acre-feet/month \\
\hline & 10172500 & 10143500 & Oct 1949 to Sep $1960^{\text {b }}$ & 3.178 & 52.744 & 0.665 & all months & acre-feet/month \\
\hline & 10170800 & 10170500 & Oct 1963 to Sep 1968 & 1.1529 & -2657 & 0.913 & Oct-Nov & acre-feet/month \\
\hline & 10170800 & 10170500 & Oct 1963 to Sep 1968 & 0.858 & 706 & 0.976 & Dec-Feb & acre-feet/month \\
\hline & 10170800 & 10170500 & Oct 1963 to Sep 1968 & 0.3661 & 2561 & 0.916 & Mar-Jul & acre-feet/month \\
\hline & 10170800 & 10170500 & Oct 1963 to Sep 1968 & 0.3012 & 2935 & 0.329 & Aug-Sep & acre-feet/month \\
\hline & 10172630 & 10170500 & Oct 1971 to Sep 1984 & 0.5908 & -2535 & 0.956 & all months & acre-feet/month \\
\hline \multirow[t]{7}{*}{ Davis County } & 10143500 & 10172200 & Oct 1980 to Apr 1999 & 0.7808 & 17.273 & 0.82 & all months & acre-feet/month \\
\hline & 10141500 & 10143500 & $\begin{array}{l}\text { Oct } 1949 \text { to Apr } 1950 \text {, } \\
\text { Oct } 1966 \text { to Sep } 2010\end{array}$ & 1.113 & 52.446 & 0.935 & all months & acre-feet/month \\
\hline & 10142000 & 10143500 & $\begin{array}{l}\text { Nov } 1971 \text { to Sep } 1975, \\
\text { May } 1985 \text { to Apr } 2008\end{array}$ & 6.2708 & -250.974 & 0.916 & all months & acre-feet/month \\
\hline & 10142500 & 10143500 & $\begin{array}{l}\text { Oct } 1949 \text { to Apr } 1950, \\
\text { Oct } 1966 \text { to Sep } 2010\end{array}$ & 0.999 & -17.956 & 0.946 & all months & acre-feet/month \\
\hline & 10143000 & 10143500 & Oct 1968 to Sep 2010 & 0.805 & -30.838 & 0.967 & all months & acre-feet/month \\
\hline & 10144000 & 10143500 & $\begin{array}{l}\text { Oct } 1949 \text { to Apr } 1950 \text {, } \\
\text { Oct } 1966 \text { to Sep } 2010\end{array}$ & 1.63 & -55.782 & 0.967 & all months & acre-feet/month \\
\hline & 10145000 & 10143500 & $\begin{array}{l}\text { Oct } 1949 \text { to Apr } 1950 \text {, } \\
\text { Oct } 1968 \text { to Sep } 2010\end{array}$ & 3.322 & -120.674 & 0.964 & all months & acre-feet/month \\
\hline \multirow{2}{*}{$\begin{array}{l}\text { Other surface } \\
\text { inflow }\end{array}$} & 10141040 & 10141000 & 1975 to 1986 & 0.0062 & 8704 & 0.944 & all months & acre-feet/yr \\
\hline & 10141400 & 10141000 & 1972 to 1984 & 0.0171 & 12,985 & 0.823 & all months & acre-feet/yr \\
\hline
\end{tabular}

${ }^{\mathrm{a}}$ The regression equation used in here is as follows: Discharge at estimated site $=A$ (discharge at measured site) $+B$; $\mathrm{R}^{2}$ is the coefficient of determination.

bJanuary-September 1982, February 1989, May 1993, October-November 1993, January-April 1995, October 1995 to September 1996, April 2000, October 2001 to September 2002, October 2005 to May 2007, September 2007 to February 2008, October-December 2008, November 2009 to February 2010.

The regression estimates of monthly surface inflows to the GSL (1950-2010) are presented in Table A2.

[48] Acknowledgments. We would like to thank Wallace Gwynn (Utah Geological Survey), Erica Gaddis (SWCA Environmental Consultants), and Craig Miller (Utah Division of Water Resources) for providing us with ion concentration and specific gravity data for the Great Salt Lake. We are indebted to the Associate Editor and two anonymous reviewers for their detailed and constructive reviews. This work was supported by the Utah Water Research Laboratory. The manuscript was edited by Carri Richards.

\section{References}

Abarbanel, H. D. I., and U. Lall (1996), Nonlinear dynamics of the Great Salt Lake: System identification and prediction, Clim. Dyn., 12, 287 297, doi:10.1007/BF00219502.

Abarbanel, H. D. I., U. Lall, Y.-I. Moon, M. E. Mann, and T. Sangoyomi (1996), Nonlinear dynamics and the Great Salt Lake: A predictable indicator of regional climate, Energy, 21, 655-665, doi:10.1016/03605442(96)00018-7.

Arnell, N. (2002), Hydrology and Global Environmental Change, 346 pp., Prentice Hall, New York.

Baskin, R. L. (2005), Calculation of area and volume for the south part of Great Salt Lake, Utah, U.S. Geol. Surv. Open File Rep., 2005-1327.

Baskin, R. L. (2006), Calculation of area and volume for the north part of Great Salt Lake, Utah, U.S. Geol. Surv. Open File Rep., 2006-1359.

Bedford, D. (2009), The Great Salt Lake: America's Aral Sea?, Environment , 51, 8-21, doi:10.3200/ENVT 51.5.8-21.

Chiew, F. H. S. (2006), Estimation of rainfall elasticity of streamflow in Australia, Hydrol. Sci. J., 51, 613-625, doi:10.1623/hysj.51.4.613.

Daly, C., M. Halbleib, J. I. Smith, W. P. Gibson, M. K. Doggett, G. H. Taylor, J. Curtis, and P. P. Pasteris (2008), Physiographically sensitive mapping of climatological temperature and precipitation across the conterminous United States, J. Climatol., 28, 2031-2064, doi:10.1002/joc.1688.
Dooge, J. C. I. (1992), Sensitivity of runoff to climate change: A Hortonian approach, Bull. Am. Meteorol. Soc., 73, 2013-2024, doi:10.1175/15200477(1992) $073<2013$ : sortcc $>2.0$. co $; 2$.

Dooge, J. C. I., M. Bruen, and B. Parmentier (1999), A simple model for estimating the sensitivity of runoff to long-term changes in precipitation without a change in vegetation, Adv. Water Resour., 23, 153-163, doi:10.1016/ s0309-1708(99)00019-6.

Fenneman, N. M. (1931), Physiography of Western United States, 534 pp., McGraw-Hill, New York.

Friedman, J. H. (1991), Multivariate adaptive regression splines, Ann. Stat., 19, 1-67, doi:10.1214/aos/1176347963.

Fu, G., M. E. Barber, and S. Chen (2007a), Impacts of climate change on regional hydrological regimes in the Spokane River watershed, J. Hydrol. Eng., 12, 452-461, doi:10.1061/(asce)1084-0699(2007)12:5(452).

Fu, G., S. P. Charles, and F. H. S. Chiew (2007b), A two-parameter climate elasticity of streamflow index to assess climate change effects on annual streamflow, Water Resour. Res., 43, W11419, doi:10.1029/2007WR 005890.

Fu, G., S. P. Charles, N. R. Viney, S. Chen, and J. Q. Wu (2007c), Impacts of climate variability on stream-flow in the Yellow River, Hydrol. Processes, 21, 3431-3439, doi:10.1002/hyp.6574.

Hamlet, A. F., and D. P. Lettenmaier (2005), Production of temporally consistent gridded precipitation and temperature fields for the continental United States, J. Hydrometeorol., 6, 330-336, doi:10.1175/JHM420.1.

Hipel, K. W., A. I. McLeod, and W. C. Lennox (1977), Advances in BoxJenkins modeling: 1. Model construction, Water Resour. Res., 13, 567575, doi:10.1029/WR013i003p00567.

Kuhnel, V., J. C. I. Dooge, J. P. J. O’Kane, and R. J. Romanowicz (1991), Partial analysis applied to scale problems in surface moisture fluxes, Surv. Geophys., 12, 221-247, doi:10.1007/bf01903420.

Lall, U., and A. Sharma (1996), A nearest neighbor bootstrap for resampling hydrologic time series, Water Resour. Res., 32, 679-693, doi:10.1029/ 95WR02966.

Lall, U., T. Sangoyomi, and H. D. I. Abarbanel (1996), Nonlinear dynamics of the Great Salt Lake: Nonparametric short-term forecasting, Water Resour. Res., 32, 975-985, doi:10.1029/95WR03402. 
Lall, U., Y. I. Moon, H. H. Kwon, and K. Bosworth (2006), Locally weighted polynomial regression: Parameter choice and application to forecasts of the Great Salt Lake, Water Resour. Res., 42, W05422, doi:10.1029/2004WR003782.

Loving, B. L., K. M. Waddell, and C. W. Miller (2000), Water and salt balance of Great Salt Lake, Utah, and simulation of water and salt movement through the causeway, 1987-98, U.S. Geol. Surv. Water Resour. Invest. Rep., 2000-4221.

Mearns, L. O., et al. (2007), The North American Regional Climate Change Assessment Program dataset, http:/www.earthsystemgrid.org/browse/ viewProject.htm?projectId=ff3949c8-2008-45c8-8e27-5834f54be50f, Natl. Cent. for Atmos. Res. Earth Syst. Grid Data Portal, Boulder, Colo [Updated 2011.]

Mearns, L. O., W. Gutowski, R. Jones, R. Leung, S. McGinnis, A. Nunes, and Y. Qian (2009), A regional climate change assessment program for North America, Eos Trans. AGU, 90, 311, doi:10.1029/2009EO360002.

Mohammed, I. N. (2006), Modeling the Great Salt Lake, MS thesis, 141 pp., Utah State Univ., Logan.

Mohammed, I. N., and D. G. Tarboton (2011), On the interaction between bathymetry and climate in the system dynamics and preferred levels of the Great Salt Lake, Water Resour. Res., 47, W02525, doi:10.1029/ 2010WR009561.

Moon, Y.-I., and U. Lall (1996), Atmospheric flow indices and interannual Great Salt Lake variability, J. Hydrol. Eng., 1, 55-62, doi:10.1061/(ASCE) 1084-0699(1996)1:2(55).

Moon, Y. I., U. Lall, and H.-H. Kwon (2008), Non-parametric short-term forecasts of the Great Salt Lake using atmospheric indices, J. Climatol., 28, 361-370, doi:10.1002/joc. 1533 .

Nash, J. E., and J. V. Sutcliffe (1970), River flow forecasting through conceptual models part I-A discussion of principles, J. Hydrol., 10, 282-290, doi:10.1016/0022-1694(70)90255-6.
R Development Core Team (2010), R: A language and environment for statistical computing, version 2.11.1, [Available at http://www.R-project. org], R Foundation for Statistical Computing, Vienna, Austria.

Sankarasubramanian, A., R. M. Vogel, and J. F. Limbrunner (2001), Climate elasticity of streamflow in the United States, Water Resour. Res., 37, 1771-1781, doi:10.1029/2000WR900330.

Schaake, J. C. (1990), From climate to flow, in Climate Change and U.S Water Resources, edited by P. E. Waggoner, pp. 177-206, John Wiley, New York.

Stumm, W., and J. J. Morgan (1981), Aquatic Chemistry: An Introduction Emphasizing Chemical Equilibria in Natural Waters, 2nd ed., 780 pp., John Wiley, New York.

Waddell, K. M., and J. D. Barton (1980), Estimated inflow and evaporation for Great Salt Lake, Utah, 1931-76, with revised model for evaluating the effects of dikes on the water and salt balance of the lake, Coop. Invest. Rep., 20, Utah Div. of Water Resour., Salt Lake City.

Waddell, K. M., and E. L. Bolke (1973), The effects of restricted circulation on the salt balance of Great Salt Lake, Utah, Water Resour. Bull. Rep. 18, Utah Geol. and Mineral Surv., Salt Lake City.

Wang, S.-Y., R. R. Gillies, J. Jin, and L. E. Hipps (2010), Coherence between the Great Salt Lake Level and the Pacific quasi-decadal oscillation, J. Clim., 23, 2161-2177, doi:10.1175/2009JCLI2979.1.

Wold, S. R., and K. M. Waddell (1994), Salt budget for west pond, Utah, April 1987 to June 1989, U.S. Geol. Surv. Water Resour. Invest. Rep., 934028.

Wold, S. R., B. E. Thomas, and K. M. Waddell (1997), Water and salt balance of Great Salt Lake, Utah, and simulation of water and salt movement through the causeway, U.S. Geol. Surv. Water Supply Pap., 2450.

Yates, D. N., and K. M. Strzepek (1998), Modeling the Nile Basin under climatic change, J. Hydrol. Eng., 3, 98-108, doi:10.1061/(asce)10840699(1998)3:2(98). 